\title{
Temporal Regulation of Nuclear Factor One Occupancy by Calcineurin/NFAT Governs a Voltage-Sensitive Developmental Switch in Late Maturing Neurons
}

\author{
Baojin Ding, ${ }^{1}$ Wei Wang, ${ }^{1}$ Tharakeswari Selvakumar, ${ }^{1}$ Hualin Simon Xi, ${ }^{2}$ Hong Zhu, ${ }^{3}$ Chi-Wing Chow, ${ }^{3}$ Jay D. Horton, ${ }^{4}$ \\ Richard M. Gronostajski, ${ }^{5}$ and Daniel L. Kilpatrick ${ }^{1}$ \\ ${ }^{1}$ Department of Microbiology and Physiological Systems and Program in Neuroscience and ${ }^{2}$ Bioinformatics Core, University of Massachusetts Medical \\ School, Worcester, Massachusetts 01655, ${ }^{3}$ Department of Molecular Pharmacology, Albert Einstein College of Medicine, Bronx, New York 10461, \\ ${ }^{4}$ Department of Molecular Genetics, University of Texas Southwestern Medical Center, Dallas, Texas 75390, and ${ }^{5}$ Department of Biochemistry, Program in \\ Neuroscience and Developmental Genomics Group, New York State Center of Excellence in Bioinformatics and Life Sciences, University at Buffalo, Buffalo \\ New York, 14203
}

Dendrite and synapse development are critical for establishing appropriate neuronal circuits, and disrupted timing of these events can alter neural connectivity. Using microarrays, we have identified a nuclear factor I (NFI)-regulated temporal switch program linked to dendrite formation in developing mouse cerebellar granule neurons (CGNs). NFI function was required for upregulation of many synapse-related genes as well as downregulation of genes expressed in immature CGNs. Chromatin immunoprecipitation analysis revealed that a central feature of this program was temporally regulated NFI occupancy of late-expressed gene promoters. Developing CGNs undergo a hyperpolarizing shift in membrane potential, and depolarization inhibits their dendritic and synaptic maturation via activation of calcineurin (CaN) (Okazawa et al., 2009). Maintaining immature CGNs in a depolarized state blocked NFI temporal occupancy of late-expressed genes and the NFI switch program via activation of the CaN/nuclear factor of activated T-cells, cytoplasmic (NFATc) pathway and promotion of late-gene occupancy by NFATc4, and these mechanisms inhibited dendritogenesis. Conversely, inhibition of the CaN/NFATc pathway in CGNs maturing under physiological nondepolarizing conditions upregulated the NFI switch program, NFI temporal occupancy, and dendrite formation. NFATc4 occupied the promoters of late-expressed NFI program genes in immature mouse cerebellum, and its binding was temporally downregulated with development. Further, NFI temporal binding and switch gene expression were upregulated in the developing cerebellum of $N f a t c 4(-I-)$ mice. These findings define a novel NFI switch and temporal occupancy program that forms a critical link between membrane potential/CaN and dendritic maturation in CGNs. CaN inhibits the program and NFI occupancy in immature CGNs by promoting NFATc4 binding to late-expressed genes. As maturing CGNs become more hyperpolarized, NFATc4 binding declines leading to onset of NFI temporal binding and the NFI switch program.

\section{Introduction}

The timing of dendrite formation and synaptogenesis is intimately involved in establishing unique patterns of neuronal connectivity (Deguchi et al., 2011; Tripodi and Arber, 2012). Accordingly, gene expression must be precisely coordinated in time to ensure that synaptic circuits properly form (Hippenmeyer et al., 2005; Di Cristo et al., 2007; Petrovic and

Received July 20, 2012; revised Nov. 8, 2012; accepted Dec. 17, 2012.

Author contributions: B.D., W.W., C.-W.C., J.D.H., R.M.G., and D.L.K. designed research; B.D., W.W., T.S., and H.Z. performed research; B.D., W.W., H.S.X., and D.L. K. analyzed data; B.D., H.S.X., and D.L.K. wrote the paper.

This work was supported by Public Health Service Grant NS063047 to D.L.K. and HL08624 (NHLBI) and C026429 (NYSTEM) to R.M.G. We thank George Gagnon, Jason Osinski, Alicia Alterio, Robert Lumley, and Amy Corron for their assistance in performing certain experiments and bioinformatic analyses.

The authors declare no competing financial interests.

Correspondence should be addressed to Daniel L. Kilpatrick, Department of Microbiology and Physiological Systems and Program in Neuroscience, University of Massachusetts Medical School, 55 Lake Avenue North, Worcester, MA 01655. E-mail: Daniel.kilpatrick@umassmed.edu.

W. Wang's present address: Advanced Cell Technology, 33 Locke Drive, Marlborough, MA 01752.

DOI:10.1523/JNEUROSCI.3533-12.2013

Copyright $\odot 2013$ the authors $\quad 0270-6474 / 13 / 332860-13 \$ 15.00 / 0$
Hummel, 2008). Temporal dysregulation leading to altered synapse formation has been implicated in several neurodevelopmental disorders (Geschwind and Levitt, 2007; Leonardo and Hen, 2008; Meredith et al., 2012).

Cerebellar granule neurons (CGNs) function in cerebellar information processing via synaptic connections with mossy fiber inputs and Purkinje cell outputs (D'Angelo et al., 2011). CGNs have been studied extensively to elucidate mechanisms governing neuronal development, including dendritogenesis and synapse formation (Goldowitz and Hamre, 1998; Hall et al., 2000; Ito and Takeichi, 2009). CGN progenitors (CGNPs) proliferate in the external germinal layer (EGL) and generate immature neurons within the premigratory zone (PMZ). CGN cell bodies later migrate inwardly until reaching the internal granule cell layer (IGL), where postmigratory CGNs form mature dendrites and synaptic connections with input neurons. Numerous genes are sequentially expressed during these different developmental stages (Goldowitz and Hamre, 1998; Furuichi et al., 2011). Much of this developmental program is recapitulated in CGN cultures (Ito 
and Takeichi, 2009; de la Torre-Ubieta et al., 2010) wherein CGNPs and immature CGNs isolated from the EGL/PMZ (Raetzman and Siegel, 1999) differentiate into IGL-like cells upon plating (Manzini et al., 2006; Wang et al., 2011).

Nuclear factor I (NFI) transcription factors are important regulators of CGN maturation (Kilpatrick et al., 2012). They are expressed throughout CGN postmitotic development and regulate parallel fiber extension, migration, dendritogenesis, and synaptogenesis (Wang et al., 2007, 2010; Piper et al., 2011). Recently, NFI proteins were shown to control the dendritogenesis-linked expression of the $\alpha 6 \mathrm{GABA}_{\mathrm{A}}$ receptor subunit (Gabra6) gene within the developing IGL (Wang et al., 2011). CGNs thus provide a robust model for exploring the programming of dendrite and synapse formation and the role of NFI proteins in these events (Kilpatrick et al., 2012).

CGNs undergo a shift in membrane potential as they differentiate, becoming increasingly hyperpolarized with maturation (Rossi et al., 1998; Cathala et al., 2003; Okazawa et al., 2009). This change in membrane potential has been implicated in the control of mouse CGN differentiation in culture and within the developing cerebellum (Nakanishi and Okazawa, 2006). In particular, depolarization of immature CGNs inhibits developmental changes in gene expression as well as dendritic and synaptic maturation via $\mathrm{Ca}^{2+}$-dependent activation of calcineurin (CaN) (Mellor et al., 1998; Ives et al., 2002; Sato et al., 2005; Iijima et al., 2009; Okazawa et al., 2009).

Here we describe an NFI-regulated temporal switch program that regulates late differentiation of postmigratory CGNs, including dendrite formation. A central feature of this program is delayed NFI occupancy of numerous genes that are temporally upregulated as CGNs mature. Further, we show that this NFI switch is directly linked to membrane potential-dependent mechanisms via its regulation by $\mathrm{CaN}$ activation of nuclear factor of activated T-cells, cytoplasmic (NFATc) transcription factors.

\section{Materials and Methods}

Animals and primary cultures. Mouse CGNs were prepared from 6-d-old CD1 mouse pups of either sex as previously described (Wang et al., 2004). Individual culture experiments were performed using cells prepared from the same litter. Cells were plated at a density of $5 \times 10^{4}$ cells $/ \mathrm{cm}^{2}$ onto chamber slides or cell culture dishes coated with poly-Dlysine/laminin (Invitrogen) in Neurobasal medium (Invitrogen) containing B-27 serum-free supplement (50×; Invitrogen) (Wang et al., 2004). The following reagents were added to culture medium $\sim 1 \mathrm{~h}$ after cell plating and were refreshed on $3 \mathrm{~d}$ in vitro (DIV): $5 \mu \mathrm{m}$ FK506 (Sigma), $1 \mu \mathrm{m}$ cyclosporin A (Sigma), $10 \mu \mathrm{m}$ nimodipine (Tocris Bioscience), $100 \mu \mathrm{M}$ kainic acid (KA; Sigma), vehicle control (dimethylsulfoxide). Cerebellar tissues were obtained from postnatal Nfatc4 $(-/-)$ mice on a C57BL/6 background as well as from wild-type (WT) C57BL/6 mice (Charles River). Nfia (-/-) mice and WT littermates were on a C57BL/6NTac background.

Plasmids and cell lines. Self-inactivating lentiviruses expressing hemagglutinin (HA)-tagged NFI dominant repressor (NFI/EnR) or Drosophila engrailed repressor domain (EnR) were described previously (Wang et al., 2004). FLAG-tagged NFATc4 proteins [(constitutively active (NFATc4-Ala) and dominant-negative NFAT (dnNFAT)] were released from their expression vectors (Chow et al., 1999; Yang et al., 2002) and inserted into $\mathrm{BamHI}$ and $\mathrm{XbaI}$ sites of the lentiviral expression vector pHR' -cPPT-CMV-W-Sin 18 (Wang et al., 2004). Human embryonic kidney 293 T cells were grown in DMEM (Invitrogen) containing 10\% heatinactivated fetal bovine serum (Invitrogen).

Lentivirus preparation and transduction of primary CGNs. Lentiviruses were generated by cotransfection of $293 \mathrm{~T}$ cells with lentiviral expression plasmid, psPAX2 and pCMV-VSVG, then concentrated and titered as previously described (Wang et al., 2005). CGN cultures were transduced on 0 DIV using MOI $=2.5-3$, yielding $80-90 \%$ cell transduction.
RNA isolation and quantitative real-time PCR. RNA was extracted from tissues or cultured cells using Tri reagent (Sigma), processed with DNAfree kit (Ambion), and complementary DNAs were prepared as described previously (Wang et al., 2007). Real-time PCRs were performed in triplicate using a StepOnePlus Real-Time PCR System (Applied Biosystems). Target transcripts were normalized to $18 \mathrm{~S}$ rRNA by the $2^{-\Delta \mathrm{Ct}}$ method, and differences relative to control samples were calculated using $2^{-\Delta \Delta \mathrm{Ct}}$ as previously described (Wang et al., 2011). Numerical values for $2^{-\Delta \Delta \mathrm{Ct}}<1.0$ were recalculated as control relative to experimental data and expressed as negative numbers. Real-time PCR primer sequences are available upon request.

Microarray and bioinformatic analyses. Total RNA was purified from CGN cultures with an RNeasy Plus Micro Kit (Qiagen). RNA quality analysis and hybridizations to GeneChip Mouse Genome 430A,B or 430 2.0 arrays (Affymetrix) were performed by the Genomics Core Facility of the University of Massachusetts Medical School. Differentially expressed genes for temporal and NFI arrays were analyzed separately. For NFI arrays (four NFI/EnR expressed vs four EnR control biological replicates), gene expression values in the Affymetrix cel files were first background corrected and normalized together using RMA algorithm (Bioconductor R package). To identify genes with robust expression, we removed probes with low expression (i.e., expression value below 40th percentile in at least seven of eight arrays). For multiple probes mapping to the same gene, only the probe showing the highest expression change for each gene was retained. Finally, moderated $t$ statistics and FDR correction (limma R package) were used to assess the significance of differential expression. NFI differentially regulated genes were defined as probes with FDR $p$ value $<0.15$ and fold change $>1.5$. Identical steps for signal normalization, background noise correction, and statistical testing were applied to temporal arrays (1.5 DIV vs 6 DIV, three biological replicates each). Differentially expressed genes were defined as having probes with FDR $p$ value $<0.1$ and fold change $>2$. We used more stringent criteria to define temporally regulated genes since the variability between replicates appeared smaller. Greater variability among the NFI/EnR array data likely reflected differing infectivities of distinct lentiviral preparations used for independent experiments. Finally, NFIregulated and temporally regulated overlap genes showed significant differential expression for the same probes in both NFI and temporal datasets. Chi-square tests were used to assess the significance of the overall overlap dataset as well as its partitioning into four NFI/temporal categories based on the directionality of expression changes.

Citations related to synaptic function, signaling, and excitability were identified in the PubMed database. Mouse gene promoter sequences were extracted from GenBank and were scanned for NFI consensus sites using the TRANSFAC database.

Chromatin immunoprecipitation assays. Chromatin immunoprecipitation (ChIP) assays were performed as previously described (Wang et al., 2011). For tissues, nuclei were first purified by Percoll gradient centrifugation (Wang et al., 2011) or by differential centrifugation $(1400 \times$ $g$ for $3 \mathrm{~min}, 4^{\circ} \mathrm{C}$ ) in $0.25 \mathrm{~m}$ sucrose. Samples were assayed by PCR using polyacrylamide gels or real-time PCR. PCR data were expressed as a percentage of input using the $2^{-\Delta \mathrm{Ct}}$ method. ChIP antibodies were to Xenopus NFIB1 (xNFIB1) (Puzianowska-Kuznicka and Shi, 1996), NF1A (Active Motif; 39036), NFATc4 (Santa Cruz Biotechnology; sc-1153), and FLAG epitope (Sigma; F1804). Pre-immune serum or normal rabbit IgG (Millipore; PP64) were used as negative controls. PCR primer sequences for ChIP assays are available upon request.

Immunofluorescence and dendritogenesis assay. Immunofluorescence was performed as in previous studies (Wang et al., 2007). Briefly, primary CGNs were cultured in coated chamber slides and then were fixed on 1.5 DIV or 2 DIV with $4 \%$ paraformaldehyde/PBS. Cells were permeabilized with $1 \%$ Triton $\mathrm{X}$ solution, incubated with $5 \%$ normal goat serum followed by primary antibodies at $4^{\circ} \mathrm{C}$ overnight and then Cy3-conjugated goat anti-rabbit IgG (NG1807775; Millipore). Dendrite assays used antiMap2 antibody (Millipore; AB5622) and $1 \mu \mathrm{g} / \mathrm{ml}$ Bisbenzimide (Sigma) to stain nuclei. Dendrite length was measured with Image Pro Plus 6.0 software. Lentiviral titrations used antibodies for HA (NFI/EnR and EnR; C29F4, Cell Signaling Technology) or FLAG (NFATc4 proteins; M2 antibody, Sigma). 
Western blot. Total nuclear proteins were prepared from cultured CGNs as previously described (Wang et al., 2004). Purified NFIA, NFIB, and NFIX proteins were purchased from Abnova. Protein samples were separated on $8 \%$ SDS-polyacrylamide gels and transferred onto Pure Nitrocellulose membranes (GE Water \& Process Technologies). Following blocking for $1 \mathrm{~h}$, blots were incubated with primary antibodies at $4^{\circ} \mathrm{C}$ overnight and then with horseradish peroxidase-conjugated secondary antibody at real time for $1 \mathrm{~h}$. Bound antibodies were detected with a chemiluminescent substrate (Thermo Scientific). Primary antibodies used were as follows: xNFIB antibody (1:200), pan-NFI antibody (1:1000; Santa Cruz Biotechnology, sc-5567), and anti-Histone H3 (1: 1000; Abnova, PAB0653).

NFAT transactivation and CaN-dependent dephosphorylation assays. To determine NFAT transcriptional activity, cultured CGNs were transduced with an NFAT dual luciferase reporter lentiviral vector ( $\mathrm{Na}$ et al., 2010) (kindly provided by the van den Brink lab, Memorial Sloan-Kettering Cancer Center, NY). NFAT trans-activation was quantified by measuring NFAT-inducible click-beetle red luciferase (CBRLuc) and normalizing activity to a constitutively expressed membrane-anchored Gaussialuciferase (extGLuc) using the Dual-Glo Luciferase Assay System (Promega). CaN-dependent dephosphorylation activity was measured using a cellular assay kit (Enzo Life Sciences) according to the manufacturer's instructions. Data were normalized to protein concentration.

Statistics. In all quantitative studies other than microarrays, data were statistically analyzed using the two-tail $t$ test. Results were expressed as the mean $\pm \mathrm{SD}$, and $p$ values $<0.05$ were considered significant.

\section{Results}

NFI controls a developmental switch in maturing CGNs

NFI proteins regulate several developmentally expressed genes in maturing CGNs (Wang et al., 2007, 2010). Here we determined whether these proteins controlled a larger temporal program using a 2D microarray analysis of temporally regulated and NFI-regulated genes. For temporal genes, we compared immature CGNs (1.5 DIV) with more differentiated (6 DIV) cultures. CGN cultures (1.5 DIV) are largely postmitotic (Wang et al., 2005) and exhibit a morphology and pattern of gene expression consistent with immature CGNs in vivo, while 6 DIV cultures resemble IGL-like CGNs (Raetzman and Siegel, 1999; Manzini et al., 2006; Wang et al., 2010, 2011). This analysis identified 844 Temporal-Up or Temporal-Down genes (Fig. 1A). NFIregulated genes were assayed in more mature 6 DIV CGN cultures that were transduced at the time of plating (0 DIV) with NFI dominant repressor (HA-NFI/EnR) or control (HA-EnR) proteins using lentiviruses (Wang et al., 2004). This identified 686 NFI-regulated genes that were either suppressed or elevated by NFI/EnR (Fig. 1A). Based on its dominant repressor function, NFI/EnR should inhibit expression of genes directly activated by NFI proteins. Consistent with this, HA ChIP detected NFI/EnR bound to the Gabra6 and

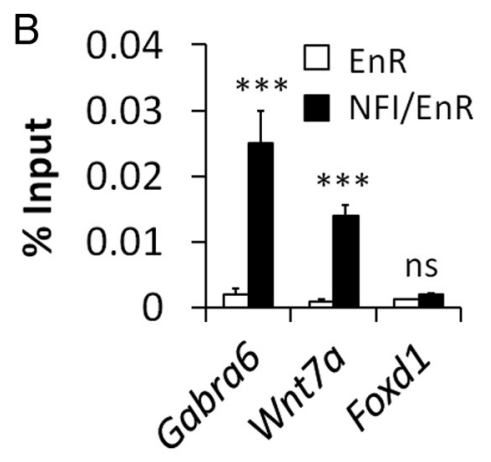

Early Late

\begin{tabular}{|c|c|}
\hline $11(5.2 \%)$ & $134(63.2 \%)$ \\
$P=0.35$ & $P<1 E-300$ \\
\hline $62(29.2 \%)$ & $5(2.4 \%)$ \\
$P=9.4 E-120$ & $P=0.2$ \\
\hline
\end{tabular}

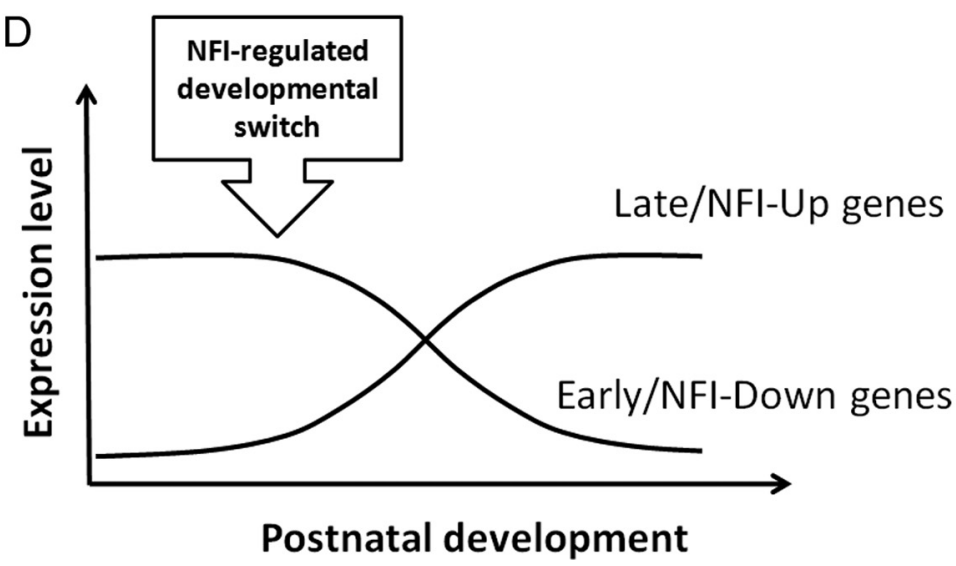

Figure 1. Identification of an NFI developmental switch program in developing CGNs. $\boldsymbol{A}$, Diagram showing temporal (844 genes) and NFI-regulated (686 genes) microarray datasets and their overlap (212 genes). B, ChIP pPCR assays were performed for (

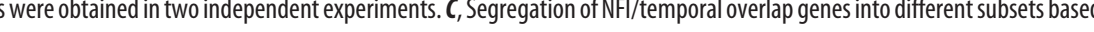
upregulate Late genes and downregulate Early genes.

Wnt7a NFI sites (Fig. 1B). Genes upregulated by the dominant repressor may have been indirectly derepressed via suppression of intermediary regulators required for their downregulation. Other mechanisms also are possible; e.g., certain genes may have been directly repressed by endogenous NFI proteins, but less efficiently by the dominant repressor resulting in their upregulation. The latter question was not further examined here.

Overlap analysis identified 212 genes that were both NFI and temporally regulated (Fig. $1 A$ ). This overlap was highly significant $(p=4.29 \mathrm{e}-222$ ). Temporal genes were enriched $\sim 8$-fold within the NFI-regulated set relative to non-NFI regulated genes, indicating the importance of NFI proteins in developmental gene regulation. Overlap genes segregated into four gene subsets based on their temporal patterns and regulation by endogenous NFI proteins (Fig. 1C): Early/NFI-Down, Early/NFI-Up, Late/NFIDown, Late/NFI-Up. Early and Late genes were temporally downregulated or upregulated on 6 DIV; NFI-Up genes were 
Table 1. Validation of NFI switch gene regulation in culture and in vivo using qRT-PCR

\begin{tabular}{|c|c|c|c|c|c|}
\hline Gene symbol & Gene ID & $\begin{array}{l}6 \text { DIV } \\
\text { versus } 0 \text { DIV }\end{array}$ & $\begin{array}{l}\text { P22 versus } \\
\text { P7 }\end{array}$ & $\begin{array}{l}\text { NFI-EnR versus } \\
\text { EnR }\end{array}$ & $\begin{array}{l}\text { Nfia }{ }^{-/-} \\
\text {versus Wt }\end{array}$ \\
\hline \multicolumn{6}{|l|}{ Late/NFI-Up } \\
\hline Wnt7a & 22421 & 12 & 9.9 & -17 & -2.9 \\
\hline Nptx1 & 18164 & 35 & 44 & -71 & -3.2 \\
\hline Rps6ka1 & 20111 & 39 & 7.1 & -42 & -3.5 \\
\hline Nab2 & 17937 & 13 & 8.2 & -10 & -3.1 \\
\hline Tesc & 57816 & 142 & 43 & -7.8 & -6.8 \\
\hline Camkk2 & 207565 & 12 & 8.1 & $-2.3^{* *}$ & -3.8 \\
\hline Camk4 & 12326 & 23 & 17 & -22 & -5.5 \\
\hline Egr1 & 13653 & -13 & 4.6 & -6.4 & $1.1 \mathrm{~ns}$ \\
\hline Ets2 & 23872 & - & - & -3.1 & -7.3 \\
\hline \multicolumn{6}{|l|}{ Early/NFI-Down } \\
\hline$D c x$ & 13193 & -5.8 & -142 & $2.6^{* *}$ & $2.6^{* *}$ \\
\hline Neurod6 & 11922 & -3.4 & -11 & $1.7^{*}$ & $1.4^{*}$ \\
\hline $\operatorname{Tgf} \beta 2$ & 21808 & -3.4 & -4.5 & $1.5^{*}$ & $1.4^{*}$ \\
\hline Met & 17295 & $-1.3^{*}$ & -4 & 6.7 & $-1.6^{*}$ \\
\hline Ect2 & 13605 & -20 & -88 & 2.8 & 3.6 \\
\hline Nhlh1 & 18071 & - & - & - & 2.3 \\
\hline \multicolumn{6}{|l|}{ Late/NFI-Down } \\
\hline Pcdh17 & 219228 & $2.7^{* *}$ & -3.6 & 14 & $-2.7^{* *}$ \\
\hline \multicolumn{6}{|l|}{ Early/NFI-Up } \\
\hline Nrcam & 319504 & 3.9 & $-1.6^{*}$ & $-2.1^{*}$ & $-2.2^{* *}$ \\
\hline Cdh10 & 320873 & $2.5^{* *}$ & $-2.9^{* *}$ & -6.4 & $-1.2 \mathrm{~ns}$ \\
\hline \multicolumn{6}{|c|}{ Additional genes } \\
\hline \multicolumn{6}{|c|}{ Late/NFI-Up } \\
\hline Kcnab1 & 16497 & - & - & -4.8 & - \\
\hline SIC12a5 & 57138 & - & - & $-2.3^{* *}$ & - \\
\hline Kcnk3 & 16527 & - & - & -6 & - \\
\hline Syn2 & 20965 & - & - & $-2.3^{* *}$ & - \\
\hline \multicolumn{6}{|l|}{ Nonoverlap } \\
\hline $1 d 2$ & 15902 & - & - & 6.4 & - \\
\hline Scrg1 & 20284 & - & - & -5.6 & - \\
\hline Hopx & 74318 & - & - & -5.3 & - \\
\hline Tiam1 & 21844 & - & - & $-20.0^{*}$ & -3.7 \\
\hline
\end{tabular}

Data are expressed as the relative difference in expression; negative values indicate reduced expression relative to controls. Dashes, not determined. $p<0.001$ except ${ }^{*} p<0.05,{ }^{* *} p<0.01$; ns, no significant difference. Data are representative of three independent experiments.

upregulated by NFI (repressed by NFI/EnR) while NFI-Down genes were inhibited by NFI (elevated by NFI/EnR) in 6 DIV cultures.

Nearly all (92\%) NFI temporal genes clustered into two groups: Early/NFI-Down (62 genes; $29 \%$ of overlap genes) and a predominant set of Late/NFI-Up genes (134; 63\% of total) (Fig. $1 C)$. This skewed distribution was also highly statistically significant (Fig. 1C), and it suggested a "developmental switch" mechanism in which NFI proteins downregulate genes expressed in immature CGNs and upregulate late-expressed genes (Fig. 1D). Based on this model, dominant repression of NFI function "trapped" CGNs in an immature state, stimulating or preventing the temporal downregulation of Early/NFI-Down gene expression, and directly or indirectly suppressing expression of Late/ NFI-Up genes.

Regulation by NFI/EnR was confirmed in CGN cultures for a total of 34 genes using qRT-PCR (Table 1; Fig. 2), including several transcripts that did not reach significance in the overlap set but were of regulatory or functional interest. For 25 genes we also determined NFI regulation in vivo using P15 Nfia-null mouse cerebellum, which showed identical trends with NFI/EnR data with the exception of Egrl (Table 1). This may reflect a compensatory or required role for other NFI family members in

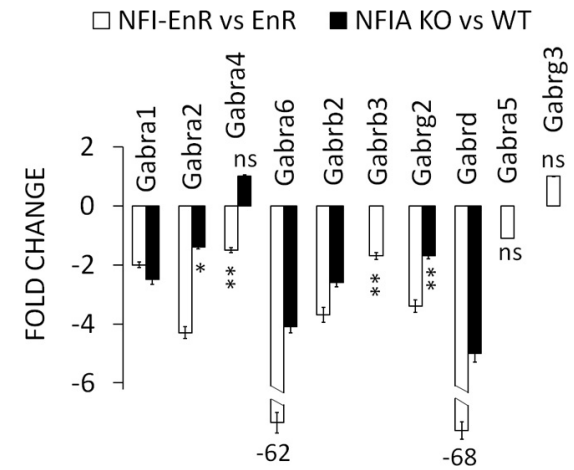

Figure 2. NFI controls $G A B A_{A}$ receptor switch gene expression. $q R T-P C R$ assays of $G A B A_{A}$ receptor subunit genes that undergo developmental changes in gene expression during CGN maturation. Changes were assessed in 6 DIV CGN cultures transduced on 0 DIV with NFI/EnR or EnR lentivirus, and in P15 Nfia $(+/+)($ WT) and $(-/-)($ KO) cerebella. Larger fold changes for the Gabra6 and Gabrd genes are shown numerically below the bars. $p<0.001$ except ${ }^{*} p<$ $0.05,{ }^{* *} p<0.01 ; \mathrm{ns}$, no significant difference. Data are representative of three independent experiments.

Egrl gene regulation. Temporal expression was also determined in culture and in vivo for 16 genes (Table 1), and 8 others (Tiam1, Ets2, Kcnk3, Slc12a5, and $\mathrm{GABA}_{\mathrm{A}}$ receptor genes (Fig. 2) were previously reported (Laurie et al., 1992; Sato et al., 2005). This revealed that the NFI switch was activated between P7 and P21, when postmigratory CGNs within the IGL form dendrites and synapses. We also identified several temporally regulated nonoverlap genes that were not dependent on NFI (Tle1, Scn2a1, Kcna1, Kcnk9, Prickle1, Rbfox3) (data not shown).

\section{NFI controls $\mathrm{GABA}_{\mathrm{A}}$ receptor maturation and synapse- related gene expression}

$\mathrm{GABA}_{\mathrm{A}}$ receptors undergo a developmental switch in subunit composition as postmigratory CGNs mature within the IGL, with $\alpha 1-, \alpha 6-, \beta 2-, \beta 3-, \gamma 2-$, and $\delta$-subunits being upregulated (Laurie et al., 1992; Zheng et al., 1993). This receptor switch is critical for controlling CGN excitability in vivo via GABA-induced tonic inhibition (Rossi and Hamann, 1998). Gabra6 ( $\alpha 6)$, Gabra1 ( $\alpha 1)$, Gabrb2 ( $\beta 2$ ), and Gabrg2 ( $\gamma 2$ ) were identified as Late/NFI-Up transcripts by microarrays, suggesting that NFI proteins regulated the $\mathrm{GABA}_{\mathrm{A}}$ receptor switch in CGNs. qRT-PCR confirmed that expression of these four genes was reduced by NFI dominant repression in CGN cultures and by Nfia deficiency in vivo (Fig. 2 ). Further, expression of the $\mathrm{GABA}_{\mathrm{A}}$ switch genes Gabrb3 ( $\beta 3$ ) and Gabrd $(\delta)$ also were dependent on NFI. Interestingly, the Gabra2 $(\alpha 2)$ and Gabra4 $(\alpha 4)$ genes, which are transiently upregulated in maturing CGNs (Laurie et al., 1992), also were regulated by NFI proteins (Fig. 2), although Gabra4 was only modestly regulated. In contrast, the developmentally unregulated Gabra5 $(\alpha 5)$ and downregulated Gabrg3 $(\gamma 3)$ receptor genes (Laurie et al., 1992) were insensitive to NFI functional disruption (Fig. 2).

Initial analysis of overlap genes showed enrichment of gene functions related to cell division in the Early/NFI-Down set (e.g., Ccna2, Cks2) and neuronal differentiation in Late/NFI-Up genes (e.g., Ntrk3, Slit3, Wnt7a), among others (data not shown). Since the NFI switch is activated as CGNs form synapses within the IGL, we performed a literature analysis of known associations of NFI-regulated temporal genes with dendritic and synaptic structure/function, excitability, and signaling. Remarkably, 63 Late/ NFI-Up genes (47\%) had known links to these events (Table 2), consistent with their temporal upregulation by NFI. In contrast, 
Table 2. NFI/Temporal overlap genes with citations related to regulation of synaptic/dendritic development, synaptic function, and signaling

\begin{tabular}{|c|c|c|c|c|c|c|c|}
\hline Late/Nfi-Up & & & & & & & Early/Nfi-Down \\
\hline Sorl1 & Cbx6 & Stxbp5I & Chn2 & Pak1 & Slc12a5 & Apoe & Stmn 1 \\
\hline KIf9 & Zdhhc18 & Wnt7a & Dact1 & Eps8 & Rasgrf1 & Cbln 3 & $C d c 20$ \\
\hline Gas6 & Ncdn & Atp1a2 & Adam 11 & Kcnk3 & Iqsec1 & Ntrk3 & Nnat \\
\hline Vsnl1 & Col19a1 & Trpm3 & Gsg11 & Tyr03 & Rap1gap & Bcan & $T g f b 2$ \\
\hline Lrrc4c & Tmeff2 & Sybu & Cacna2d3 & SIC4a4 & Rora & Etv1 & Slitrk5 \\
\hline Ptprt & Gas7 & Syn2 & Tem163 & Nck1 & Dlgap1 & Gabra6* & Sncaip \\
\hline Dpp10 & Ppfia4 & Unc13c & Syt1 & Lrrtm3 & Inadl & Gabrb2* & Dpys/5 \\
\hline Nup210 & Boc & $L r r 3 c b$ & Gprc5b & Sparc & Kcnab1 & Gabrg2* & \\
\hline Smarcd3 & Gprc5b & Kcnh1 & Sept8 & Prune2 & Nptx1 & Gabra1* & \\
\hline
\end{tabular}

Hyperlinks to publications relevant to synapse and dendrite function, localization, regulation, signaling, or excitability are provided in the online version of the article. *See text.

A
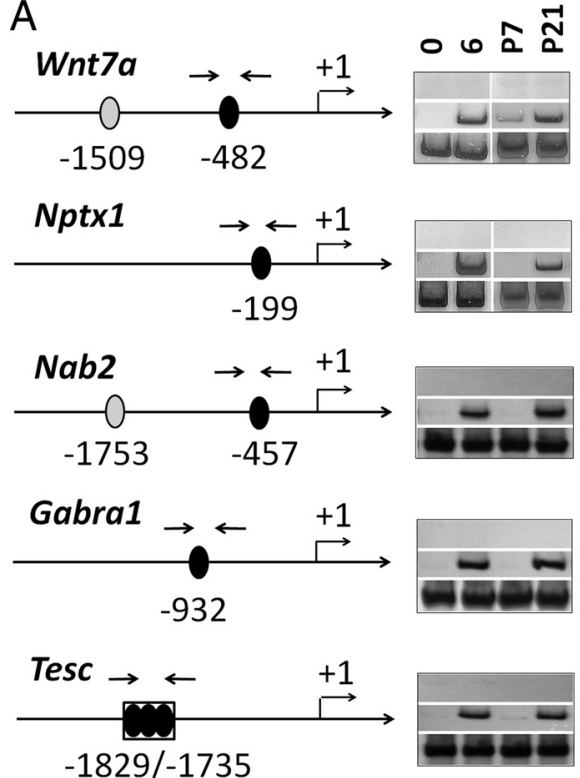
$\alpha-N F I$

Input

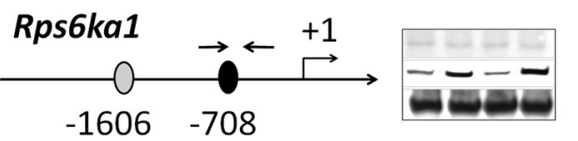

Pre

$\alpha-N F I$ Input

Efnb1

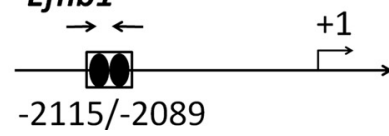

Pre $\alpha-N F I$ Input
B

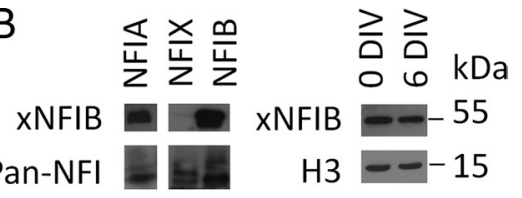

C

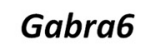

Wnt7a

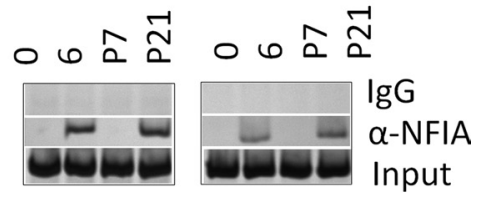

Nptx1 Foxd1

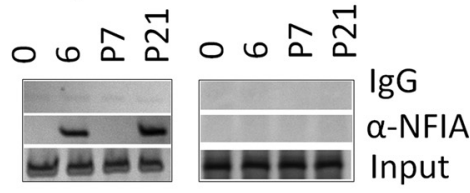

D

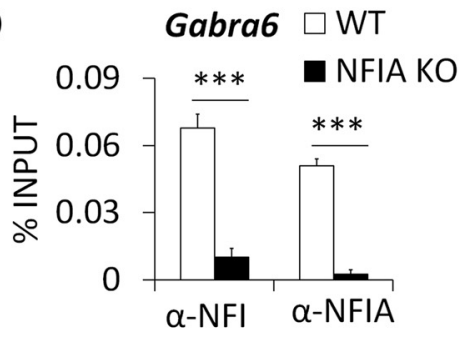

Figure 3. NFl occupancy of Late/NFI-Up genes is temporally regulated. $\boldsymbol{A}$, Left, Schematic of predicted NFI binding sites in the $5^{\prime}$-flanking regions of the indicated gene promoters. Open ovals, weak NFI binding sites; filled ovals, strong NFI binding sites. Arrows, position of primers used for ChIP qPCR. Right, Temporal NFI ChIP results. Pre, pre-immune serum; $\alpha$-NFI, anti-xNFIB1 serum. Similar ChIP results were obtained in two or three experiments for each gene. $\boldsymbol{B}$, Left, Characterization of the specificity of XNFIB1 antibody for expressed NFI family proteins on Western blots. Pan-NFI antibody staining of the same lanes is shown below. Right, NFI protein expression in nuclear extracts of immature and more differentiated CGN cultures detected with xNFIB1 antibody. Histone H3 (H3) served as a loading control. Data are representative of two independent experiments. C, ChIP assays showed that NFIA binds in a temporally delayed manner to Late/NFI-Up genes. Foxd1 genomic sequences served as a negative control. Identical patterns were observed in two independent experiments. D, ChIP/qPCR assays of P15 Nfia (+/+) (WT) and ( - / - ) (K0) mouse cerebella confirmed that occupancy of the Gabra6 NFI site as detected by xNFIB1 ( $\alpha$-NFI) and NFIA antibodies was dependent on NFIA. ${ }^{* * *} p<0.001$. Negative control antibody values were subtracted to yield specific antibody ChIP/qPCR signals. Data are representative of two independent experiments.

only seven Early/Down genes (11\%) had known synapse-related activities or localization, indicating continuing functions of this small gene cohort in more mature CGNs following their developmental downregulation.

\section{NFI occupancy of numerous Late/NFI-Up genes is} temporally regulated

The timing of Gabra6 gene expression during CGN development is linked to delayed NFI binding to its promoter (Wang et al., 2011). Further, NFI proteins and their nuclear DNA binding activity are constitutively expressed during CGN maturation in cul- ture and in vivo (Wang et al., 2011), indicating that NFI temporal occupancy of the Gabra6 gene is regulated at the level of chromatin interactions. We therefore examined whether temporally regulated NFI chromatin occupancy was a more global mechanism for six other Late/NFI-Up genes (Wnt7a, Nptx1, Nab2, Gabra1, Tesc, Rps6ka1) using ChIP. The 5'-flanking regions for each gene contained one or more consensus NFI sites, at least one of which showed detectable NFI occupancy (Fig. $3 A$ ). In each case, the timing of NFI binding mirrored temporal expression: binding was undetectable or low in 0 DIV cells consisting of premigratory CGNPs/CGNs derived from the EGL/PMZ (Raetzman and 

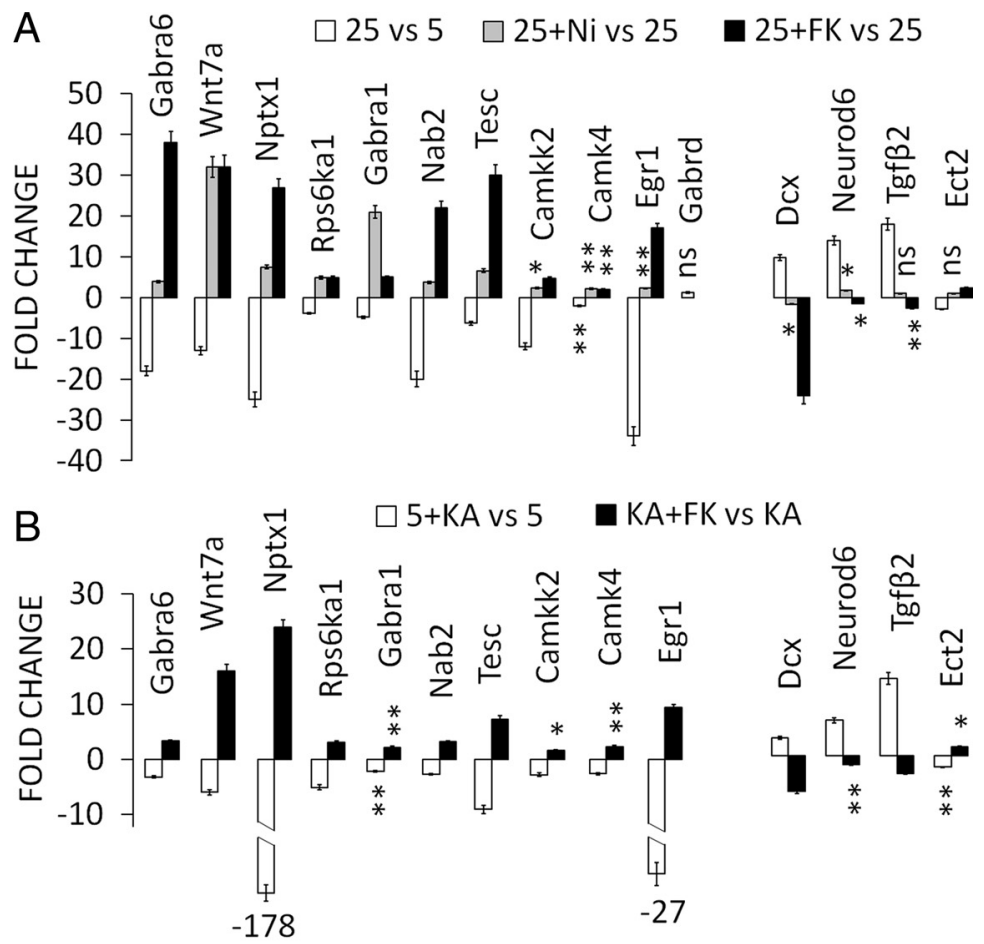

C

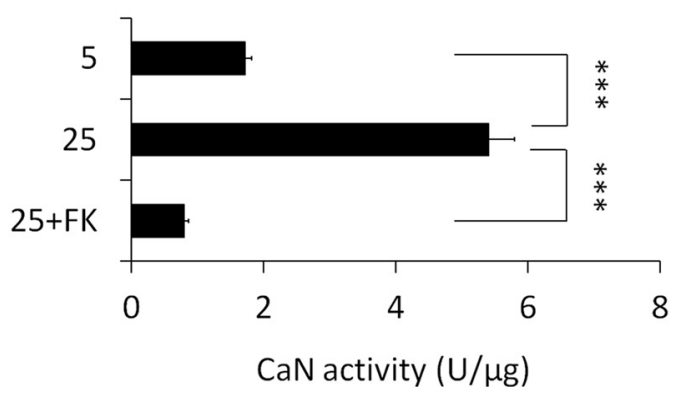

Figure 4. Regulation of the NFI switch program by membrane depolarization and CaN. qRT-PCR assays in $\boldsymbol{A}$ and $\boldsymbol{B}$ were performed for Late/NFI-Up genes (left) and Early/NFI-Down genes (right). $A$, Depolarization by $25 \mathrm{~mm} \mathrm{KCl}$ culture medium (25) inhibits the NFI gene switch in 6 DIV CGNs, which is reversed by inhibitors of L-type VGCCs (nimodipine, Ni) and of CaN (FK506, FK). CGNs cultured in medium containing $5 \mathrm{~mm} \mathrm{KCl} \mathrm{(5).} \mathrm{B,} \mathrm{KA} \mathrm{inhibits} \mathrm{NFI} \mathrm{switch} \mathrm{gene} \mathrm{expression} \mathrm{in} \mathrm{CGNs} \mathrm{cultured} \mathrm{to} 6$ DIV in $5 \mathrm{~mm}$ $\mathrm{KCl}$-containing medium (5), which is reversed by FK506. Large fold-change values for Nptx1 and Egr1 are shown numerically. $p<$ 0.001 except ${ }^{*} p<0.05,{ }^{* *} p<0.01 ; n$, no significant difference. C, CaN activity is stimulated in depolarized CGN cultures. CGNs were cultured in medium containing either $5 \mathrm{~mm} \mathrm{KCl} \mathrm{(5)} \mathrm{or} 25 \mathrm{~mm} \mathrm{KCl} \mathrm{(25)} \pm$ FK506 to 6 DIV and CaN activity was determined in soluble cell extracts. Stimulation of phosphatase activity in depolarizing medium was prevented by the CaN inhibitor FK506. ${ }^{* * *} p<0.001$. Data in $A-C$ are representative of three independent experiments.

Siegel, 1999) and in the P7 cerebellum composed mainly of immature postmigratory CGNs from the IGL (Wang et al., 2011), but was markedly elevated in more mature (6 DIV) CGN cultures and P21 mouse cerebellum. In contrast, the Efnb1 gene, which is a direct NFI target (Wang et al., 2007) expressed at similar levels in immature and more differentiated CGNs (data not shown), exhibited constitutive NFI binding to its cognate promoter site (Fig. 3A). Delayed NFI occupancy was thus a common and specific temporal mechanism for many Late/NFI-Up genes in CGNs.

Temporal ChIP assays were performed with an anti-Xenopus NFIB1 (-xNFIB1) antibody, which recognized mammalian NFIB and NFIA, but not NFIX (Fig. 3B). Further, the abundance and mobility of NFI proteins detected by this antibody did not vary significantly with CGN maturation (Fig. 3B), as shown previously using pan-NFI antibodies (Wang et al., 2011). Since knockout studies implicated NFIA in regulation of the switch program, we also confirmed its temporal occupancy for several Late/Up genes in developing CGNs and cerebellum (Fig. 3C). Further, we confirmed that ChIP signals for both anti-xNFIB1 and NFIA antibodies were markedly reduced in chromatin from P15 Nfia-null mouse cerebella (Fig. 3D). Thus, NFIA appears to be a direct regulator of the NFI temporal program in CGNs via its delayed occupancy of Late/NFI-Up genes.

\section{Depolarization blocks NFI switch expression via activation of L-type $\mathrm{Ca}^{2+}$ channels and $\mathrm{CaN}$}

A membrane potential-regulated developmental program was previously identified in which depolarization induced by elevated extracellular $\left[\mathrm{K}^{+}\right]$inhibited the upregulation of numerous genes expressed in more mature CGNs and stimulated or maintained several genes expressed in immature CGNs (Sato et al., 2005). This voltage-sensitive pattern was similar to that of the NFI switch program, and comparison of the NFI- and $\mathrm{KCl}-$ temporal gene cohorts identified 19 commonly regulated temporal genes, including Gabra6, Gabra1, Gabrd, Camkk2, Wnt7a, Nptx1, Tiam1, Slc12a5, Kcnk3, Dcx, Neurod6, Tgfb2, and Cdh10. This suggested that at least a portion of the NFI switch program was sensitive to membrane potential in maturing CGNs. qRT-PCR analysis confirmed that numerous Late/NFI-Up genes were inhibited by $25 \mathrm{~mm} \mathrm{KCl}$ in 6 DIV CGN cultures, while several Early/NFI-Down genes were elevated (Fig. 4A). This included several $\mathrm{KCl}$ regulated genes that were not previously identified by Sato et al. (Nab2, Camk4, Egr1, and Ect2). Several KCl-sensitive genes detected by Sato et al. were not regulated by NFI (e.g., Kcna1, Tle1, and Prickle1) (data not shown). Not all temporal mRNAs examined segregated into these two KCl-regulatory/NFI-regulatory patterns; for example, transcripts for the Early/NFI-Down gene Ect2 were repressed by depolarization, and the Late/NFI-Up gene Gabrd was relatively insensitive to $25 \mathrm{~mm}$ $\mathrm{KCl}$ (Fig. 4A) as previously reported (Sato et al., 2005).

A similar switch pattern was observed in CGNs treated with KA (Fig. 4B), which also depolarizes CGNs, raises intracellular $\left[\mathrm{Ca}^{2+}\right]$ (Courtney et al., 1990), and inhibits maturationdependent gene expression (Iijima et al., 2009) via activation of AMPA/kainate receptors. Thus, the NFI switch program is more generally sensitive to membrane depolarization-dependent mechanisms.

Elevated $\mathrm{KCl}$ increases steady-state $\mathrm{Ca}^{2+}$ levels in mouse CGNs via L-type voltage-gated calcium channels (VGCCs) (Sato et al., 2005). Nimodipine, a specific inhibitor of L-type VGCCs, derepressed Late-Up gene expression in CGNs cultured in $25 \mathrm{~mm}$ $\mathrm{KCl}$ (Fig. $4 A$ ). In contrast, only one Early/NFI-Down gene, $D c x$, showed some reversal of the stimulatory effects of depolarization in 6 DIV CGNs, indicating the involvement of additional 


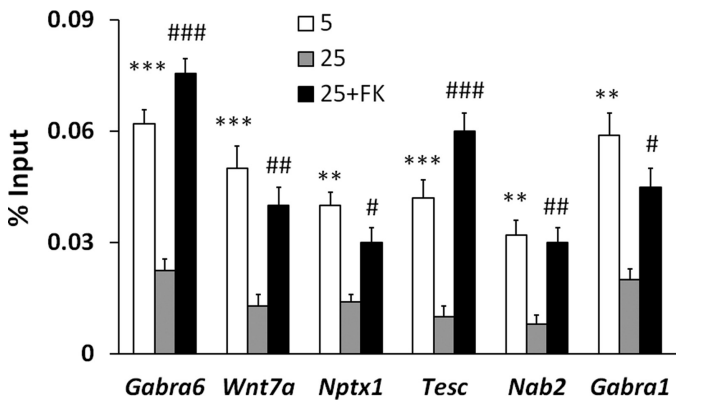

Figure 5. NFI temporal occupancy is suppressed by depolarization in a CaN-dependent manner. CGNs were cultured in $5 \mathrm{~mm}$ or $25 \mathrm{~mm} \mathrm{KCl} \pm$ FK506 until 6 DIV and then assayed for NFI occupancy of the indicated Late/NFI-Up genes using ChIP qPCR. Negative control antibody signals were subtracted from ChIP/qPCR values in each case. $\mathrm{KCl}(25 \mathrm{~mm})$ blocked the temporal increase in NFI binding, and CaN antagonism using FK506 reversed this inhibitory effect; $5,5 \mathrm{~mm}$ $\mathrm{KCl} ; 25,25 \mathrm{~mm} \mathrm{KCl} ; \mathrm{FK}$, FK506; 25 versus $5:{ }^{* *} p<0.01$; ${ }^{* * *} p<0.001$; ( $25+\mathrm{FK}$ ) versus 25 : $\# p<0.05$; \#\#p $<0.01$; \#\#\# <0.001. Data are representative of three independent experiments.

depolarization-sensitive mechanisms in the regulation of this gene subset. This was not further investigated here.

CaN activation has been implicated in depolarizationdependent regulation of numerous genes in CGNs (Guerini et al., 2000; Ives et al., 2002; Kramer et al., 2003; Sato et al., 2005; Iijima et al., 2009). To address its role in the NFI switch, we first confirmed that CaN-dependent dephosphorylation activity was stimulated ( $\sim 3$-fold) in 6 DIV CGNs cultured in $25 \mathrm{~mm} \mathrm{KCl}$ and that this activation was blocked by the CaN inhibitor FK506 (Fig. $4 C)$. FK506 reversed inhibition by $25 \mathrm{mM} \mathrm{KCl}$ or KA for all Late-Up genes examined (Fig. 4A,B). Similar results were obtained with the $\mathrm{CaN}$ antagonist cyclosporine $\mathrm{A}$ (data not shown). In contrast to nimodipine, FK506 significantly suppressed depolarization-induced elevation of the Early-Up genes $D c x$, Neurod6, and Tgfb2, consistent with earlier findings (Sato et al., 2005).

\section{Membrane depolarization and CaN activation prevent NFI temporal binding}

Since delayed occupancy is a central feature of the NFI switch program, we asked whether NFI binding to Late/NFI-Up genes was sensitive to $\mathrm{K}^{+}$depolarization. NFI association with chromatin was repressed in 6 DIV CGNs cultured in $25 \mathrm{~mm} \mathrm{KCl}$ for all six genes tested (Gabra6, Wnt7a, Nptx1, Tesc, Nab2, Gabra1) (Fig. 5). Further, these inhibitory effects were reversed by the $\mathrm{CaN}$ inhibitor FK506 (Fig. 5). Thus, temporal NFI occupancy was a primary target of depolarization-induced suppression of Late/Up genes mediated by $\mathrm{CaN}$, including the $\mathrm{GABA}_{\mathrm{A}}$ switch genes $\mathrm{Ga}$ bra6 and Gabra1.

\section{NFAT activation represses the NFI temporal switch}

Previous studies found no evidence for differential phosphorylation of NFI proteins in maturing CGNs (Wang et al., 2011). Consistent with this, $25 \mathrm{~mm} \mathrm{KCl} \mathrm{(} \pm$ FK506) did not alter the amounts of nuclear NFI proteins or their electrophoretic mobilities in maturing CGN cultures (Fig. 6A). This result indicated that CaN activation likely modified other proteins that regulate the NFI switch. NFATc proteins are transcription factors that are regulated via CaN-dependent nuclear translocation (Nguyen and Di Giovanni, 2008), and NFATc4 nuclear localization is stimulated in depolarized neurons, including CGNs (Graef et al., 1999; Benedito et al., 2005). Using a lentiviral NFAT reporter, we confirmed that depolarization of CGNs stimulated NFAT transcrip-
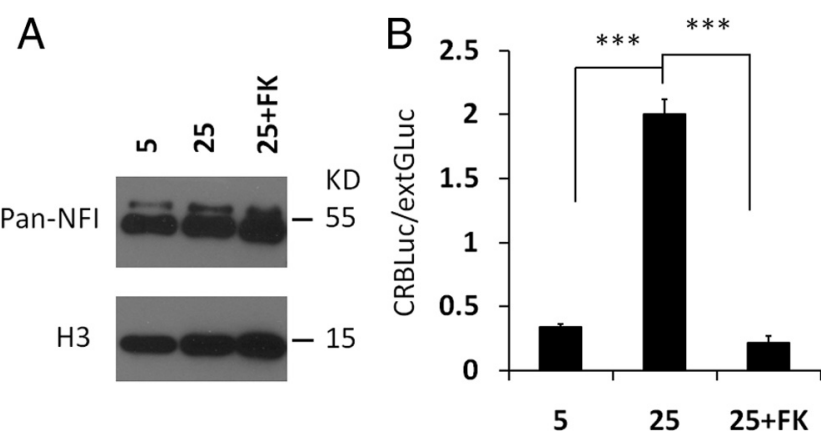

Figure 6. Depolarizing conditions have no effect on NFI proteins but stimulate NFAT transcriptional activity via CaN. $A$, Western blot of NFI proteins in 6 DIV CGNs cultured in $5 \mathrm{~mm} \mathrm{KCI} \mathrm{(5)}$ or in $25 \mathrm{~mm} \mathrm{KCl} \mathrm{(25)} \pm$ the CaN inhibitor FK506. Histone H3 (H3) served as a loading control. $\boldsymbol{B}$, CGNs were transduced with NFAT dual-reporter lentivirus on 0 DIV and cultured as in $A$ to 6 DIV. NFAT transcriptional activity was then determined in cell extracts by assaying luciferase activity. ${ }^{* * *} p<0.001$. Data are representative of either two $(\boldsymbol{A})$ or three $(\boldsymbol{B})$ independent experiments.

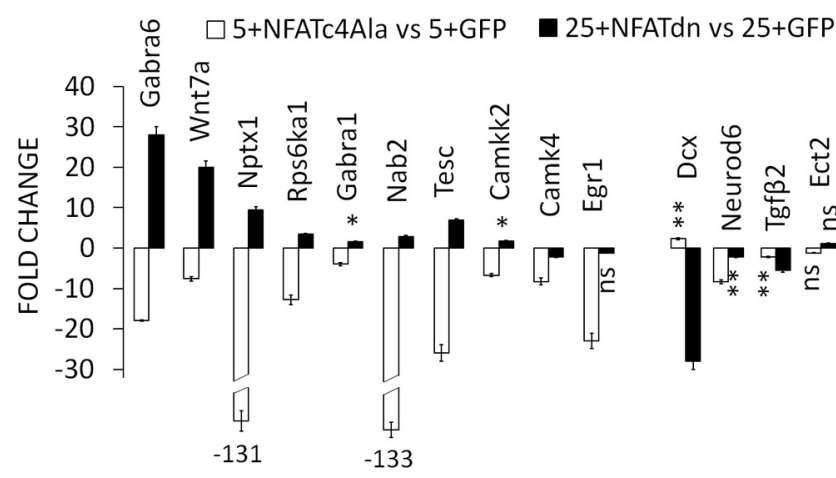

Figure 7. NFAT proteins regulate NFI switch gene expression. CGNs were transduced on 0 DIV with GFP or NFATc4-Ala lentiviruses and cultured in $5 \mathrm{~mm} \mathrm{KCl} \mathrm{medium} \mathrm{(5),} \mathrm{or} \mathrm{were} \mathrm{trans-}$ duced with GFP- or dnNFAT-expressing lentiviruses and cultured in depolarizing ( $25 \mathrm{~mm} \mathrm{KCl-}$ containing) medium (25). Cells were harvested on 6 DIV and assayed by qRT-PCR. Late/NFI-Up genes are shown on the left, Early/NFI-Down genes on the right. $p<0.001$ except ${ }^{*} p<0.05$, ${ }^{* *} p<0.01 ; \mathrm{ns}$, no significant difference. Data are representative of three independent experiments.

tional activity (Fig. 6B). We then examined the effects of blocking $\mathrm{Ca}^{2+} / \mathrm{CaN}$-dependent NFATc nuclear translocation by expressing a dominant-negative form of NFATc4 (dnNFAT) (Chow et al., 1999). DnNFAT significantly reversed depolarizationdependent inhibition of nearly all Late-Up genes tested in CGNs cultured in $25 \mathrm{~mm} \mathrm{KCl} \mathrm{(Fig.} \mathrm{7).} \mathrm{Similarly,} \mathrm{dnNFAT} \mathrm{prevented}$ upregulation of Early-Down genes by $25 \mathrm{~mm} \mathrm{KCl}$ with the exception of the noncanonical Ect2 gene, which was unaffected (Fig. 7). Thus, suppression of the NFI switch program by depolarization was largely dependent on activation of endogenous NFAT proteins.

Since nuclear translocation of NFATc4 is stimulated in depolarized neurons, we tested the effects of FLAG-tagged NFATc4 (NFATc4-Ala) that constitutively translocates to the nucleus and regulates transcription (Yang et al., 2002). In CGNs maturing in physiological medium (5 mM KCl), NFATc4-Ala strongly repressed all Late-Up genes examined (Fig. 7). Further, the EarlyDown gene $D c x$ was upregulated by NFATc4-Ala while Neurod6 and Tgfb2 were inhibited (Fig. 7), suggesting direct or indirect repressive effects on the latter genes due to constitutive NFATc activity. Thus, enhanced NFATc4 activity in nondepolarized CGNs reproduced many of the effects of $25 \mathrm{~mm} \mathrm{KCl}$ on NFI switch program expression. 


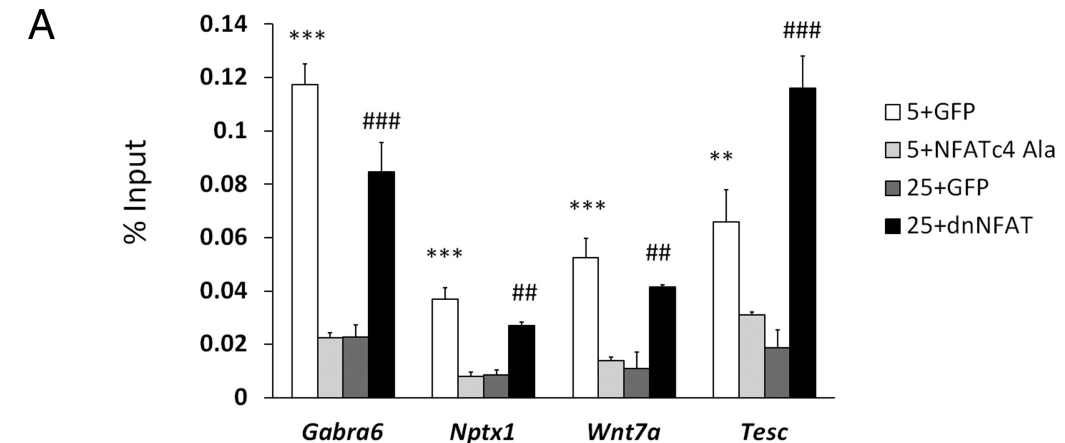

B

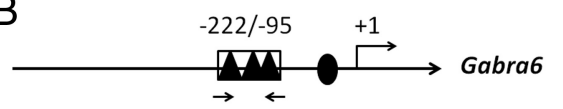

C
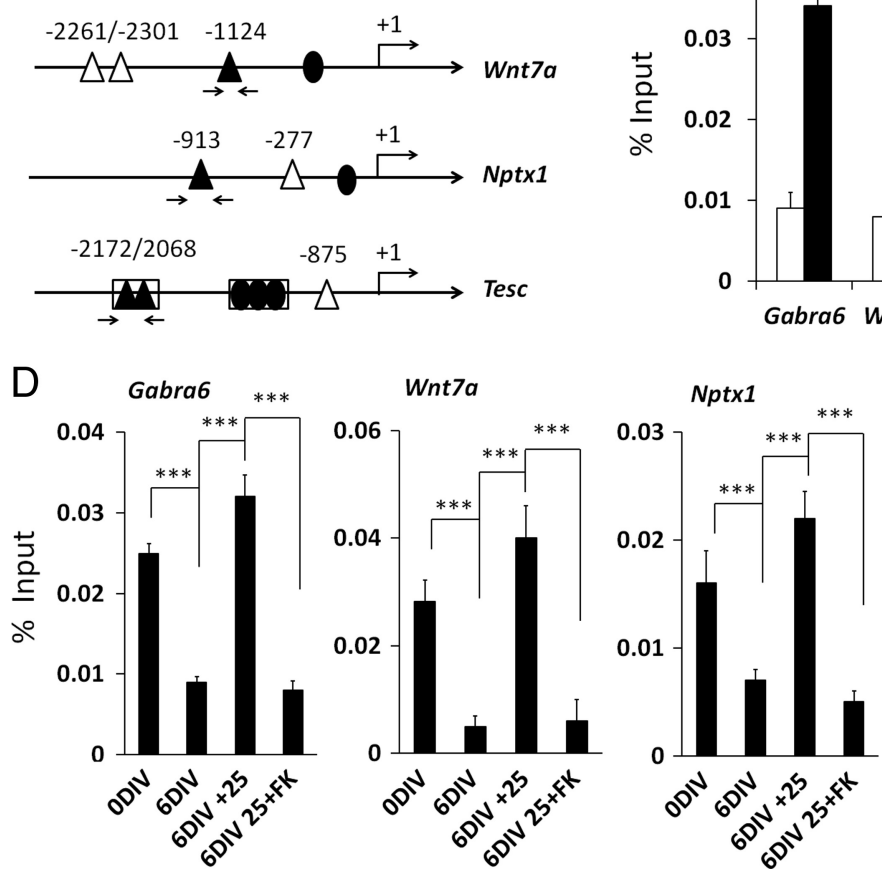

Figure 8. NFAT proteins regulate NFI binding in depolarized CGNs. A, CGNs transduced with lentiviruses expressing NFATC4-Ala, dnNFAT, or GFP were cultured in medium containing 5 or $25 \mathrm{~mm} \mathrm{KCl}$ to 6 DIV. NFI binding was determined by ChIP qPCR. $(5+$ NFATc4-Ala) versus $(5+\mathrm{GFP}){ }^{* *} p<0.01$; ${ }^{* * *} p<0.001 ;(25+\mathrm{dnNFAT})$ versus $(25+\mathrm{GFP})$ :\#\#p $<0.01$; \#\#\# $<0.001 . \boldsymbol{B}$, NFAT binding sites in the $5^{\prime}$-flanking regions of four Late/NFI-Up gene promoters. Open triangles, weak NFAT binding sites; filled triangles, strong NFAT binding sites; filled ovals, regions of NFI temporal occupancy. Positions of ChIP qPCR primers are shown by arrows. $\boldsymbol{C}$, ChIP qPCR assay of NFATc4-Ala binding to NFAT binding sites (filled triangles in $\boldsymbol{B}$ ) using anti-FLAG antibody. $\boldsymbol{D}$, ChIP qPCR assay of endogenous NFATc4 binding in CGN cultures in $5 \mathrm{~mm}(0,6 \mathrm{DIV})$ and $25 \mathrm{~mm} \mathrm{KCl}$ (6 DIV \pm FK506). $\boldsymbol{A}, \boldsymbol{C}, \boldsymbol{D}$, Control antibody ChIP values were subtracted to give specific signal; ${ }^{* *} p<0.01 ;{ }^{* * *} p<0.001$. Data are representative of two $(\boldsymbol{A}, \boldsymbol{C})$ or three $(\boldsymbol{D})$ independent experiments.

NFAT proteins control NFI occupancy in depolarized CGNs Since depolarization inhibits NFI temporal interactions with chromatin, we examined whether NFAT proteins specifically regulated NFI binding of Late/NFI-Up genes. We focused on four genes showing the most robust derepression by dnNFAT ( $\mathrm{Ga}$ bra6, Wnt7a, Nptx1, Tesc). dnNFAT expression reversed the inhibitory effects of depolarizing medium on NFI occupancy in each case (Fig. 8A). Conversely, constitutively active NFATc4-Ala inhibited NFI binding to these genes in CGNs cultured in nondepolarizing ( $5 \mathrm{~mm} \mathrm{KCl}$ ) medium (Fig. $8 A$ ).

The actions of elevated NFAT activity on NFI occupancy may have been direct or indirect. Sequence analysis identified multiple consensus NFAT binding sites near the regions of NFI occupancy within the four Late-Up gene promoters, suggesting

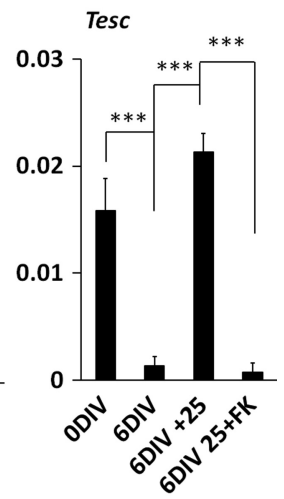

possible direct NFAT interactions (Fig. $8 B)$. To test this, CGN cultures were transduced with FLAG-tagged NFATc4-Ala and assayed by ChIP on 6 DIV. Elevated FLAG signal was detected within specific NFAT-site regions for all four promoters (Fig. 8C). Similarly, endogenous NFATc4 occupancy of Late/NFI-Up genes was markedly increased in nontransduced 6 DIV CGNs cultured in $25 \mathrm{~mm} \mathrm{KCl}$ (Fig. $8 D$ ). Thus, NFATc4 occupancy was elevated under conditions of reduced NFI occupancy of Late/NFI-Up genes, consistent with a direct inhibitory effect of this factor on the NFI switch program in depolarized CGNs.

\section{Effect of NFAT proteins on}

dendritogenesis in depolarized CGNs Both disruption of NFI function and depolarization inhibit dendrite maturation by CGNs, and $\mathrm{CaN}$ activation is required for membrane potential-dependent inhibition (Wang et al., 2007; Okazawa et al., 2009). We therefore examined whether NFAT proteins also mediated membrane potential actions on dendrite formation. Elevated $\mathrm{KCl}$ inhibited dendrite length when compared with normal (5 mM) culture medium, and this effect was substantially reversed by dnNFAT (Fig. 9A). Reciprocally, constitutively active NFATc4-Ala repressed CGN dendrite extension in $5 \mathrm{~mm} \mathrm{KCl}$ cultures (Fig. 9A). NFAT proteins therefore appear to be an integral part of a voltage-sensitive pathway regulating dendrite formation in maturing CGNs.

\section{Endogenous $\mathrm{CaN}$ and NFAT proteins regulate dendrite formation in nondepolarized CGNs}

Maturation-dependent reduction of $\mathrm{CaN}$ activity has been proposed to promote the differentiation of postmigratory CGNs within the developing postnatal IGL (Nakanishi and Okazawa, 2006). However, a direct test of CaN function in CGNs differentiating under normal, nondepolarized circumstances was not previously addressed, to our knowledge. Consistent with this hypothesis, CaN activity declined as CGNs matured in physiological culture medium (Fig. $9 B)$. Further, FK506 treatment increased dendrite extension by immature CGNs in $5 \mathrm{~mm} \mathrm{KCl}$ cultures (Fig. 9C). Similarly, dnNFAT enhanced dendritic length in CGNs maturing in physiological medium (Fig. 9C). Thus, endogenous CaN and NFAT proteins repress dendrite emergence during onset of differentiation by immature CGNs.

\section{$\mathrm{CaN}$ and NFATc4 regulate switch expression and NFI} occupancy during normal CGN differentiation Based on the above findings, we examined whether $\mathrm{CaN}$ dependent mechanisms also regulated the NFI switch program in 
CGNs maturing under physiological conditions. Treatment of CGN cultures with FK506 in medium containing $5 \mathrm{~mm} \mathrm{KCl}$ enhanced Late/NFI-Up gene expression and decreased transcripts for the Early/ NFI-Down genes Dcx and Tgfb2 (Fig. $10 A)$. Switch-enhancing effects were observed in both less mature (3 DIV) and more mature (6 DIV) cultures, although they were greater at 3 DIV for several genes, consistent with elevated CaN activity in immature CGNs. These results suggested an inhibitory function for $\mathrm{CaN}$ on the NFI switch program during normal differentiation of CGNs.

To examine the role of endogenous NFAT proteins in regulating the NFI switch, we first determined whether endogenous NFATc4 occupied Late/ NFI-Up gene promoter sites in CGNs maturing under physiological conditions. Robust NFATc4 binding was detected for the Gabra6, Wnt7a, Nptx1, and Tesc promoters in 0 DIV CGNs derived from the EGL/PMZ, as well as in the P7 cerebellum composed mainly of immature CGNs in the IGL (Wang et al., 2011) (Figs. 8D, $10 B)$. Further, NFATc4 occupancy of each site markedly declined in more differentiated, 6 DIV CGN cultures and in the P15 cerebellum (Figs. 8D,10B), consistent with an inhibitory effect on Late/NFI-Up temporal expression in immature CGNs.

To address NFATc4 function more directly, we examined the impact of NFATc4 deficiency on expression of the NFI temporal program. Cerebella from Nfatc4 knock-out mice were examined at P7-P9, when expression of the NFI switch program is largely repressed and NFATc4 binding to Late/Up gene promoters is robust, as well as at P15 when NFATc4 occupancy is low and the switch program is highly expressed. Expression of numerous Late/NFI-Up genes was significantly upregulated in Nfact4null cerebella at each age (Fig. 10C). Further, downregulation of the Early/NFI-Down gene Dcx was enhanced during this period. In contrast, Rbfox $3 / \mathrm{NeuN}$, which is upregulated as CGNs mature (Weyer and Schilling, 2003) and is not regulated by NFI (data not shown), was not altered by Nfatc4 deficiency (Fig. 10C). Thus, enhanced expression of the NFI switch program in the developing $N f a t c 4$-null cerebellum was not due to global changes in maturation-associated gene expression. Western analysis also confirmed that NFI protein levels and mobilities were unchanged in postnatal Nfatc4 (-I-) cerebellum (data not shown).

The pattern of NFATc4 temporal occupancy of Late/NFI-Up genes inversely mirrored that for NFI binding (Figs. 3A, 10B). ChIP analysis revealed that NFI binding to the four Late/NFI-Up promoters increased severalfold in $\mathrm{P} 9 \mathrm{Nfatc4}(-/-)$ cerebellum relative to WT, and remained significantly elevated at P15 (Fig. 10D). Thus, endogenous NFATc4 inhibits NFI occupancy of Late/NFI-Up genes in the developing postnatal mouse cerebellum.
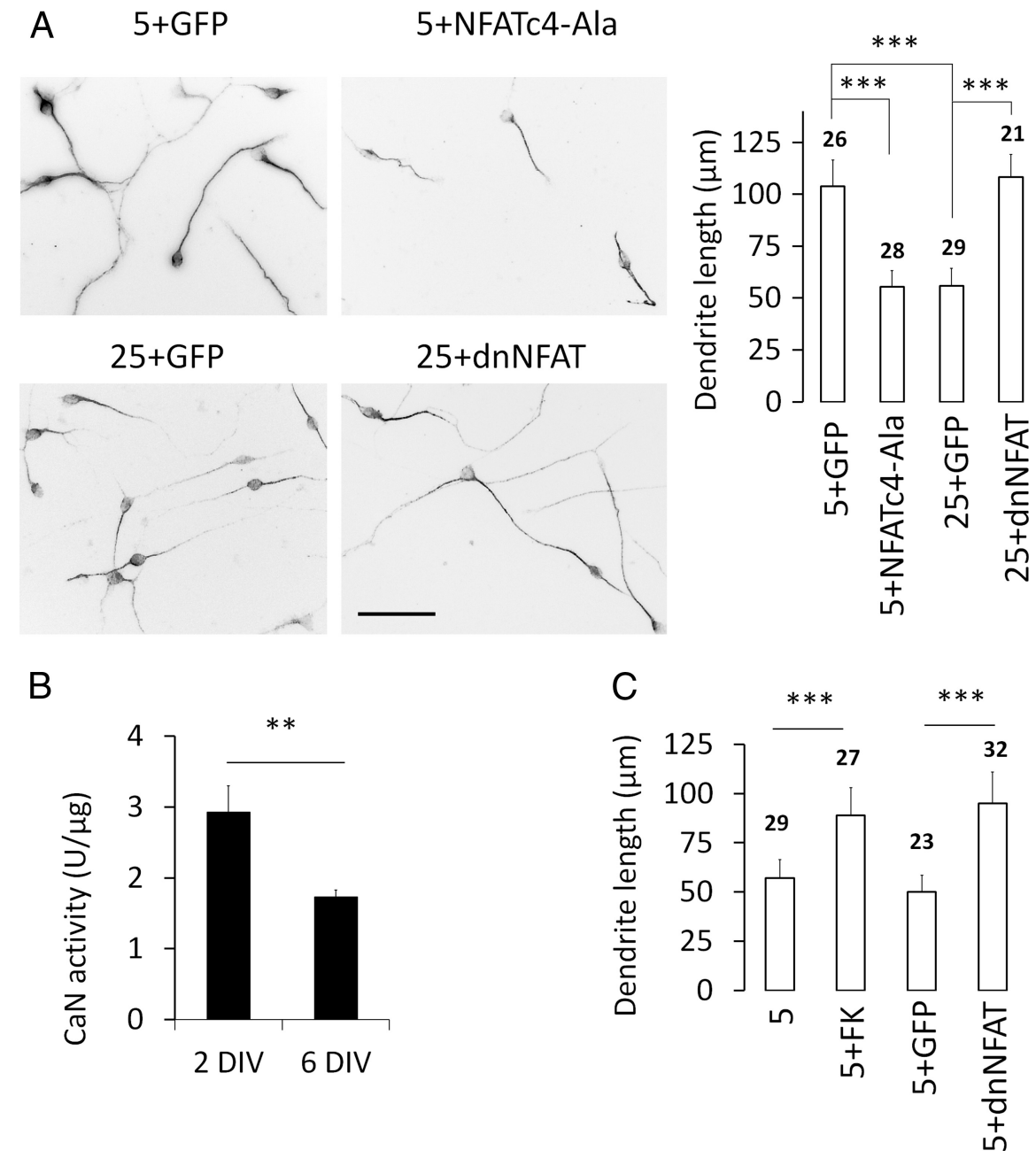

Figure 9. Regulation of CGN dendritogenesis by NFAT proteins. $\boldsymbol{A}$, Dendrite length was analyzed on 2 DIV in CGNs transduced with lentiviruses expressing GFP or NFATC4-Ala and cultured in $5 \mathrm{~mm} \mathrm{KCl} \mathrm{medium,} \mathrm{and} \mathrm{with} \mathrm{GFP} \mathrm{or} \mathrm{dnNFAT} \mathrm{viruses} \mathrm{and} \mathrm{cultured} \mathrm{in}$ medium. Grayscale images were inverted to provide better visual clarity. Left, Photomicrographs of Map2 decreases as CGNs mature. CaN activity was assayed in extracts of immature (2 DIV) and more mature (6 DIV) CGN cultures. ${ }^{* *} p<$ 0.01. C, Dendrite lengths for (GNs cultured to 1.5 DIV in standard ( $5 \mathrm{~mm} \mathrm{KCl}$ ) medium with and without FK506 or transduced with either GFP or dnNFAT viruses. $\boldsymbol{A}, \boldsymbol{C}$, The number of cells analyzed under each condition is shown above the histograms. ${ }^{* * *} p<$ 0.001 . For each part, data are representative of three independent experiments.

\section{Discussion}

The $\mathrm{GABA}_{\mathrm{A}}$ receptor switch and formation of inhibitory synapses between CGNs and GABAergic Golgi type II neurons are critical for cerebellar information flow (Hamann et al., 2002), and their completion coincides with eye opening and enhanced motor activity in rodents (Tia et al., 1996). Thus, the timing of these events is important for developmental onset of sensorimotor function. The present studies reveal a central role for NFI in regulating a late developmental switch program in CGNs that becomes active during a period (P7-P15) dominated by dendritic and synaptic maturation within the IGL. In this process, genes required for mature $\mathrm{GABA}_{\mathrm{A}}$ receptor function and dendrite and synapse formation are upregulated and "immature" genes are downregulated. Delayed NFI occupancy of late-expressed genes is a key feature of this program, coinciding with upregulation of Late/NFI-Up gene expression.

Membrane depolarization is frequently linked with the promotion of neuronal maturation. For example, depolarizing actions of GABA on immature neurons are thought to play a key 

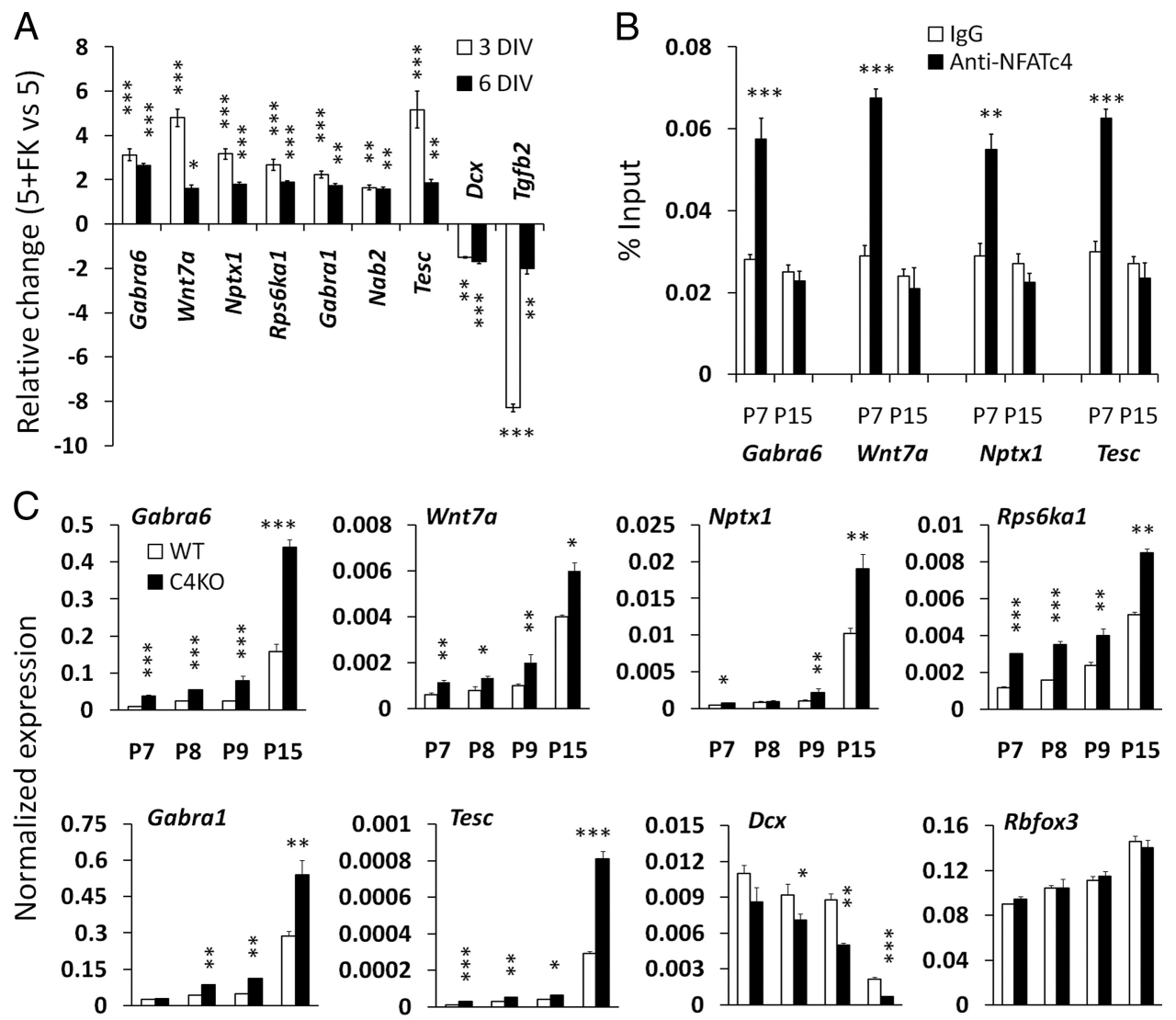

P7 P8 P9 P15

P7 P8 P9 P15

P7 P8 P9 P15

P7 P8 P9 P15
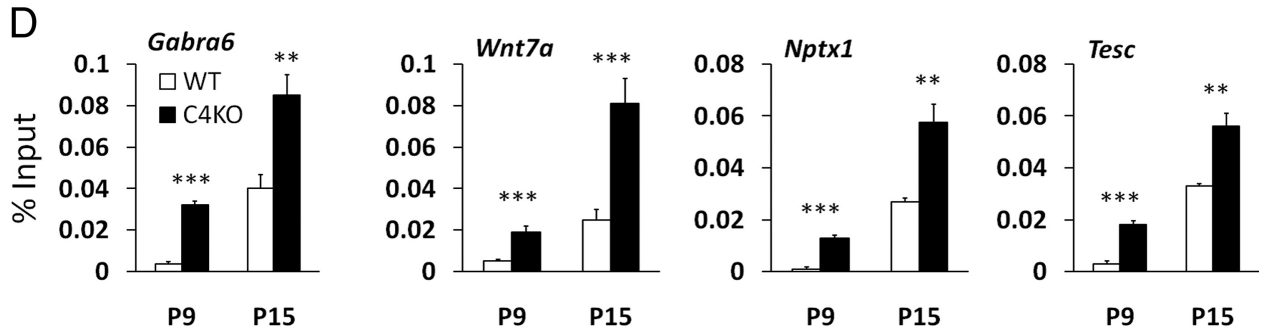

Figure 10. Regulation of the NFI switch by CaN and NFATc4 in CGNs differentiating in culture and in vivo. $\boldsymbol{A}$, Differential expression of Late/NFI-Up genes in standard (5 mm KCl) culture medium with and without FK506. CGN cultures were assayed at 3 (open bars) and 6 (filled bars) DIV. Positive values indicate upregulation and negative values indicate downregulation. $\boldsymbol{B}$, NFATc 4 temporal occupancy of Late/NFI-Up genes declines in the developing cerebellum. ChIP qPCR analysis of NFAT binding sites (Fig. 8B) was performed for P7 and P15 mouse cerebellum. C, Differential expression of NFI switch genes determined by qRT-PCR in Nfatc4-null (C4KO) and WT mouse cerebellum. Rbfox3 (NeuN) served as a non-NFI regulated negative control. D, NFI occupancy was determined by ChIP qPCR in Nfatc4-deficient (C4KO) and WT cerebellum at P9 and P15. Negative control antibody values were subtracted to show specific binding. No significant differences except ${ }^{*} p<0.05 ;{ }^{* *} p<$ $0.01 ;{ }^{* * *} p<0.001$. Data are representative of three $(\boldsymbol{A}, \boldsymbol{C})$ or two $(\boldsymbol{B}, \boldsymbol{D})$ independent experiments.

role in corticogenesis and neuronal differentiation (Wang and Kriegstein, 2009; Kilb et al., 2011). However, depolarizing conditions can also block differentiation of neurons, particularly late events linked to dendritic morphology and synaptic development (Sohya et al., 2007; Okazawa et al., 2009). Inhibition of mouse CGN maturation by depolarization-induced CaN activation has been well documented (Guerini et al., 2000; Ives et al., 2002; Kramer et al., 2003; Sato et al., 2005; Iijima et al., 2009; Okazawa et al., 2009). Our studies reveal that the NFI switch program and NFI temporal occupancy are critical targets linking depolarization and CaN activation via L-type VGCCs to inhibition of dendrite formation in CGNs, with NFATc4 being an important intermediary regulator (Fig. 11). Further, these voltage-sensitive mechanisms regulate the NFI switch program and dendrite formation in CGNs differentiating under normal, nondepolarizing conditions.
Our present findings suggest a model in which CaN/NFATc4 inhibit the NFI switch program during development in vivo, delaying and modulating the magnitude of a significant portion of its expression in immature postmigratory CGNs in the IGL (Fig. 11). Declining CaN activity and NFATc4 occupancy as CGNs differentiate leads to derepression and is permissive for activation of numerous late-maturation genes associated with dendrite formation, as well as suppression of Early/NFI-Down genes. Downregulation of Early/NFI-Down genes is apparently indirect via undefined repressive factors or signaling pathways that are stimulated by NFI trans-activation. Developmental changes in resting membrane potential, which becomes more hyperpolarized as CGNs mature (Rossi et al., 1998; Cathala et al., 2003; Okazawa et al., 2009), appear to regulate late CGN maturation and dendrite formation via $\mathrm{Ca}^{2+}$-dependent regulation of $\mathrm{CaN}$ (Nakanishi and Okazawa, 2006; Okazawa et al., 2009). Extrinsic and intrinsic 
mechanisms that promote hyperpolarization of maturing CGNs may therefore be important upstream drivers of NFI temporal occupancy and the NFI switch within the IGL via CaN/NFATc4 (Fig. 11). An interesting feature of the NFI temporal program is the regulation of several ion channel, transporter and receptor genes that control membrane potential and excitability, including Slc12a5/Kcc2, Kcnk3/ Task1, Kcnab1/K $\mathrm{K}$ b1.3, and $\mathrm{GABA}_{\mathrm{A}}$ receptor subunits. This raises the possibility that NFI temporal programming and CGN excitability may reinforce each other during development, forming a selfamplifying positive feedback loop. Similar mechanisms also may operate in other neurons that undergo developmental membrane hyperpolarization (Ramoa and McCormick, 1994; Zhou and Hablitz, 1996; Tyzio et al., 2003).

The timing of neurogenesis has been linked to the formation of discrete patterns of synaptic circuitry for different neuronal subtypes (Tripodi and Arber, 2012). Thus, molecular mechanisms initiated during neuronal birth appear to contribute significantly to the timing of synaptogenesis and circuit formation. In the context of CGN development, postnatal CGNP transplantation experiments showed that maturation-dependent expression of the NFI switch gene Gabra6 was independent of in vivo developmental and regional cues (Bahn et al., 1999). Sim-

ilarly, Gabra6 gene expression is maintained in CGNs of HNF3 $\beta$ transgenic mice that fail to properly migrate to the IGL (Zhou et al., 2001). These and other findings suggested that intrinsic timing mechanisms initiated during CGNP cell cycle exit trigger dendritogenesis-associated gene expression in maturing CGNs (Mellor et al., 1998; Bahn et al., 1999). NFI temporal occupancy and its regulation by developmental changes in $\mathrm{CaN}$ activity and NFATc4 binding may therefore be part of an internal timing mechanism contributing to dendritic development and its associated gene expression in CGNs. Modulation of these timing mechanisms by environmental factors also may be important for appropriate magnitude and temporality of NFI switch gene expression.

NFI proteins function at multiple stages of CGN development (Wang et al., 2007), and a key question is how they regulate such a diversity of events occurring over varying time frames. The present studies provide insight into their regulation of gene expression specifically required for postmigratory CGN maturation via delayed promoter occupancy. Since NFI proteins and their nuclear DNA binding activity are not temporally upregulated in maturing CGNs (Wang et al., 2011), additional transcriptional and chromatinrelated factors presumably contribute to the specificity and timing of their binding and regulation of Late/NFI-Up genes. NFATc4 appears to be an important direct regulator of these events: it binds to numerous Late/NFI-Up gene promoters in immature CGNs, and it is required to prevent premature and excessive NFI occupancy in the developing postnatal cerebellum. The trans-repressor REST was recently shown to occupy the Gabra6 promoter and to inhibit its bind-
P7 IGL (Immature CGNs) Depolarization
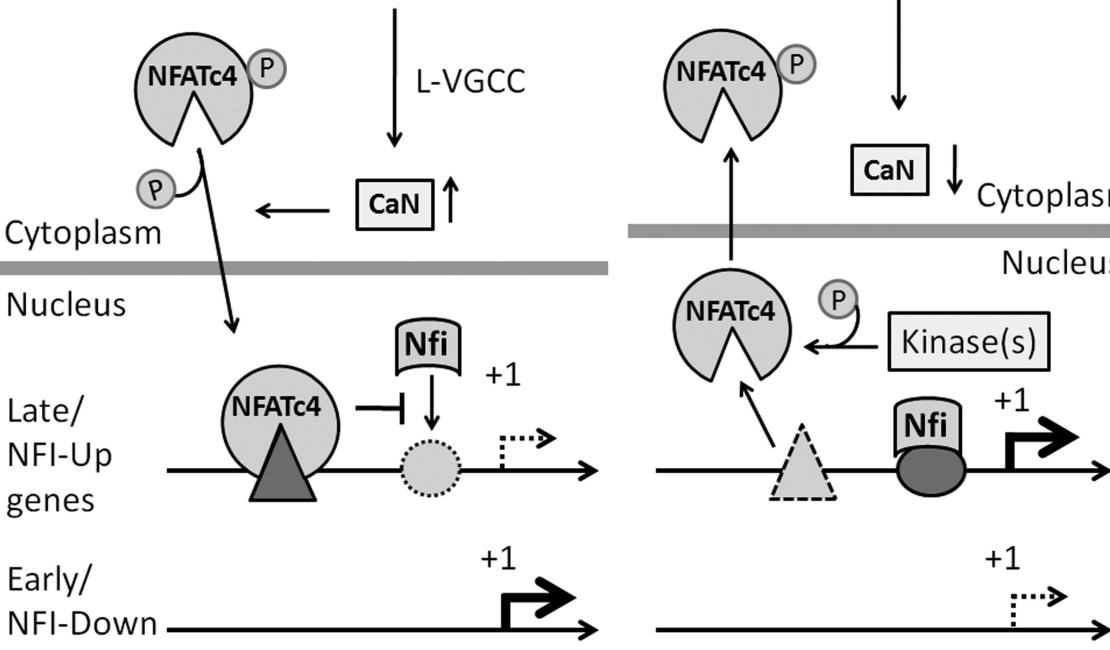

B (Mature CGNs) Hyperpolarization

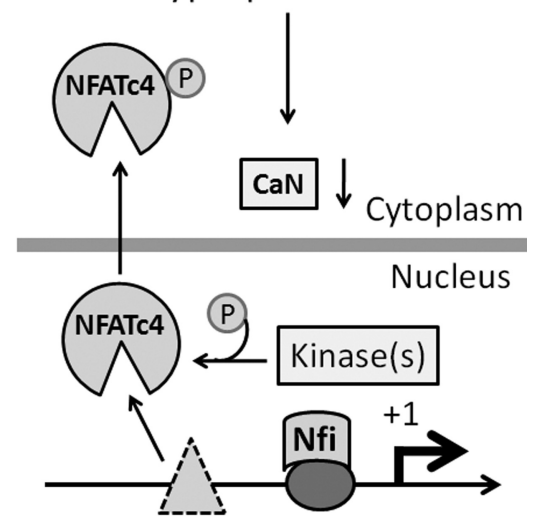

Figure 11. Model for developmental regulation of the NFI switch program in maturing CGNs. A, In the early postnatal cerebelCarive expression. Reduced CaN/NFATC4 activity also downregulates Early/NFI-Down genes presumably via indirect repressive mechanisms. A shift in resting membrane potential from less to more hyperpolarized in maturing CGNs promotes temporal downregulation of the CaN/NFATc4 pathway and activates NFI temporal binding and the NFI switch during cerebellar development.

ing by NFI in CGNPs and premigratory CGNs derived from the EGL/PMZ (Wang et al., 2011). REST occupancy is depleted in the P7 cerebellum when NFI binding remains low, indicating additional mechanisms function to prevent premature NFI binding in CGNs within the immature IGL. Our findings implicate NFATc4 in the continued repression of NFI occupancy of the Gabra6 gene in immature postmigratory CGNs in the early postnatal (e.g., P7) IGL following REST dismissal. NFATc4 also limits the magnitude of NFI occupancy of multiple Late/NFI-Up promoters as well as switch program expression in more mature CGNs at P15 (Fig. 10C,D). NFATc4 also may repress Late/NFI-Up genes (and possibly enhance Early/NFI-Down gene expression) via additional, NFI-independent mechanisms.

NFATc4 was previously implicated in neuronal development and function, including axonogenesis and survival, neurotrophin signaling, and memory formation in mice (Graef et al., 2003; Nguyen et al., 2009; Vashishta et al., 2009; Quadrato et al., 2012). Our studies define a novel role for NFATc4 in late CGN development via its temporally downregulated chromatin occupancy. They also identify numerous NFATc4 neuronal targets involved in dendrite/synapse formation, implicating this factor as an important direct regulator of late-maturation gene expression in CGNs.

Nfia knock-out mice exhibit severe neurological disruptions, including tremor and diminished cerebellar foliation consistent with altered cerebellar function (das Neves et al., 1999; Wang et al., 2007). Dendrite and synapse formation within the IGL are also altered in Nfia (-/-) mice (Wang et al., 2007, 2010), and as 
shown here NFIA occupancy of Late/NFI-Up genes is temporally regulated. Further, development of both CGNs and cortical pyramidal neurons is delayed in Nfia-null mice (Wang et al., 2007; Piper et al., 2010), consistent with a more general temporal function for this protein in maturing neurons. It is noteworthy that patients with NFIA haploinsufficiency exhibit developmental delays in motor skills and language (Lu et al., 2007; Shaikh et al., 2011), both of which involve cerebellar function (Strick et al., 2009). NFIA and other NFI family members may therefore control important timing mechanisms in CGNs that are involved in developmental delay in both humans and mice.

Formation of distinct patterns of neuronal connectivity has been linked to specific temporal schedules of synaptogenesis (Deguchi et al., 2011; Tripodi and Arber, 2012). Thus, the timing of presynaptic and postsynaptic maturation is a key developmental step in establishing the complexity of neural circuitry that characterizes $\mathrm{CNS}$ structure and function. This requires appropriate temporal regulation of gene expression involved in dendritic and synaptic maturation, and disrupted temporal expression can dramatically alter synaptic circuitry (Hippenmeyer et al., 2005; Petrovic and Hummel, 2008). Altered expression of temporally regulated genes during critical time windows affecting synaptic maturation has been proposed to underlie several neurodevelopmental disorders (Meredith et al., 2012). The molecular mechanisms that control these temporal synaptic events are largely unknown. The present studies provide insight into the importance of NFI proteins in the onset of dendrite-related gene expression via their temporally regulated occupancy of synapse-related target genes. An interesting possibility is that altered NFI switch programming and NFI temporal occupancy contribute to disrupted timing of dendrite and synapse formation associated with one or more neurodevelopmental disorders.

\section{References}

Bahn S, Wisden W, Dunnett SB, Svendsen C (1999) The intrinsic specification of gamma-aminobutyric acid type A receptor alpha6 subunit gene expression in cerebellar granule cells. Eur J Neurosci 11:2194-2198. CrossRef Medline

Benedito AB, Lehtinen M, Massol R, Lopes UG, Kirchhausen T, Rao A, Bonni A (2005) The transcription factor NFAT3 mediates neuronal survival. J Biol Chem 280:2818-2825. Medline

Cathala L, Brickley S, Cull-Candy S, Farrant M (2003) Maturation of EPSCs and intrinsic membrane properties enhances precision at a cerebellar synapse. J Neurosci 23:6074-6085. Medline

Chow CW, Rincón M, Davis RJ (1999) Requirement for transcription factor NFAT in interleukin-2 expression. Mol Cell Biol 19:2300-2307. Medline

Courtney MJ, Lambert JJ, Nicholls DG (1990) The interactions between plasma membrane depolarization and glutamate receptor activation in the regulation of cytoplasmic free calcium in cultured cerebellar granule cells. J Neurosci 10:3873-3879. Medline

D’Angelo E, Mazzarello P, Prestori F, Mapelli J, Solinas S, Lombardo P, Cesana E, Gandolfi D, Congi L (2011) The cerebellar network: from structure to function and dynamics. Brain Res Rev 66:5-15. CrossRef Medline

das Neves L, Duchala CS, Tolentino-Silva F, Haxhiu MA, Colmenares C, Macklin WB, Campbell CE, Butz KG, Gronostajski RM, Godinho F (1999) Disruption of the murine nuclear factor I-A gene (Nfia) results in perinatal lethality, hydrocephalus, and agenesis of the corpus callosum. Proc Natl Acad Sci U S A 96:11946-11951. CrossRef Medline

de la Torre-Ubieta L, Gaudillière B, Yang Y, Ikeuchi Y, Yamada T, DiBacco S, Stegmüller J, Schüller U, Salih DA, Rowitch D, Brunet A, Bonni A (2010) A FOXO-Pak1 transcriptional pathway controls neuronal polarity. Genes Dev 24:799-813. CrossRef Medline

Deguchi Y, Donato F, Galimberti I, Cabuy E, Caroni P (2011) Temporally matched subpopulations of selectively interconnected principal neurons in the hippocampus. Nat Neurosci 14:495-504. CrossRef Medline

Di Cristo G, Chattopadhyaya B, Kuhlman SJ, Fu Y, Bélanger MC, Wu CZ, Rutishauser U, Maffei L, Huang ZJ (2007) Activity-dependent PSA ex- pression regulates inhibitory maturation and onset of critical period plasticity. Nat Neurosci 10:1569-1577. CrossRef Medline

Furuichi T, Shiraishi-Yamaguchi Y, Sato A, Sadakata T, Huang J, Shinoda Y, Hayashi K, Mishima Y, Tomomura M, Nishibe H, Yoshikawa F (2011) Systematizing and cloning of genes involved in the cerebellar cortex circuit development. Neurochem Res 36:1241-1252. CrossRef Medline

Geschwind DH, Levitt P (2007) Autism spectrum disorders: developmental disconnection syndromes. Curr Opin Neurobiol 17:103-111. CrossRef Medline

Goldowitz D, Hamre K (1998) The cells and molecules that make a cerebellum. Trends Neurosci 21:375-382. CrossRef Medline

Graef IA, Mermelstein PG, Stankunas K, Neilson JR, Deisseroth K, Tsien RW, Crabtree GR (1999) L-type calcium channels and GSK-3 regulate the activity of NF-ATc4 in hippocampal neurons. Nature 401:703-708. CrossRef Medline

Graef IA, Wang F, Charron F, Chen L, Neilson J, Tessier-Lavigne M, Crabtree GR (2003) Neurotrophins and netrins require calcineurin/NFAT signaling to stimulate outgrowth of embryonic axons. Cell 113:657-670. CrossRef Medline

Guerini D, Wang X, Li L, Genazzani A, Carafoli E (2000) Calcineurin controls the expression of isoform $4 \mathrm{CII}$ of the plasma membrane $\mathrm{Ca}(2+)$ pump in neurons. J Biol Chem 275:3706-3712. CrossRef Medline

Hall AC, Lucas FR, Salinas PC (2000) Axonal remodeling and synaptic differentiation in the cerebellum is regulated by WNT-7a signaling. Cell 100:525-535. CrossRef Medline

Hamann M, Rossi DJ, Attwell D (2002) Tonic and spillover inhibition of granule cells control information flow through cerebellar cortex. Neuron 33:625-633. CrossRef Medline

Hippenmeyer S, Vrieseling E, Sigrist M, Portmann T, Laengle C, Ladle DR, Arber S (2005) A developmental switch in the response of DRG neurons to ETS transcription factor signaling. PLoS Biol 3:e159. CrossRef Medline

Iijima T, Emi K, Yuzaki M (2009) Activity-dependent repression of Cbln1 expression: mechanism for developmental and homeostatic regulation of synapses in the cerebellum. J Neurosci 29:5425-5434. CrossRef Medline

Ito S, Takeichi M (2009) Dendrites of cerebellar granule cells correctly recognize their target axons for synaptogenesis in vitro. Proc Natl Acad Sci U S A 106:12782-12787. CrossRef Medline

Ives JH, Drewery DL, Thompson CL (2002) Neuronal activity and its influence on developmentally regulated GABA(A) receptor expression in cultured mouse cerebellar granule cells. Neuropharmacology 43:715-725. CrossRef Medline

Kilb W, Kirischuk S, Luhmann HJ (2011) Electrical activity patterns and the functional maturation of the neocortex. Eur J Neurosci 34:1677-1686. CrossRef Medline

Kilpatrick DL, Wang W, Gronostajski R, Litwack ED (2012) Nuclear factor I and cerebellar granule neuron development: an intrinsic-extrinsic interplay. Cerebellum 11:41-49. CrossRef Medline

Kramer D, Fresu L, Ashby DS, Freeman TC, Genazzani AA (2003) Calcineurin controls the expression of numerous genes in cerebellar granule cells. Mol Cell Neurosci 23:325-330. CrossRef Medline

Laurie DJ, Wisden W, Seeburg PH (1992) The distribution of thirteen GABAA receptor subunit mRNAs in the rat brain. III. Embryonic and postnatal development. J Neurosci 12:4151-4172. Medline

Leonardo ED, Hen R (2008) Anxiety as a developmental disorder. Neuropsychopharmacology 33:134-140. CrossRef Medline

Lu W, Quintero-Rivera F, Fan Y, Alkuraya FS, Donovan DJ, Xi Q, TurbeDoan A, Li QG, Campbell CG, Shanske AL, Sherr EH, Ahmad A, Peters R, Rilliet B, Parvex P, Bassuk AG, Harris DJ, Ferguson H, Kelly C, Walsh CA, et al. (2007) NFIA haploinsufficiency is associated with a CNS malformation syndrome and urinary tract defects. PLoS Genet 3:e80. CrossRef Medline

Manzini MC, Ward MS, Zhang Q, Lieberman MD, Mason CA (2006) The stop signal revised: immature cerebellar granule neurons in the external germinal layer arrest pontine mossy fiber growth. J Neurosci 26:60406051. CrossRef Medline

Mellor JR, Merlo D, Jones A, Wisden W, Randall AD (1998) Mouse cerebellar granule cell differentiation: electrical activity regulates the GABAA receptor alpha 6 subunit gene. J Neurosci 18:2822-2833. Medline

Meredith RM, Dawitz J, Kramvis I (2012) Sensitive time-windows for susceptibility in neurodevelopmental disorders. Trends Neurosci 35:335344. CrossRef Medline

Na IK, Markley JC, Tsai JJ, Yim NL, Beattie BJ, Klose AD, Holland AM, Ghosh 
A, Rao UK, Stephan MT, Serganova I, Santos EB, Brentjens RJ, Blasberg RG, Sadelain M, van den Brink MR (2010) Concurrent visualization of trafficking, expansion, and activation of T lymphocytes and T-cell precursors in vivo. Blood 116:e18-e25. CrossRef Medline

Nakanishi S, Okazawa M (2006) Membrane potential-regulated Ca2+ signalling in development and maturation of mammalian cerebellar granule cells. J Physiol 575:389-395. CrossRef Medline

Nguyen T, Di Giovanni S (2008) NFAT signaling in neural development and axon growth. Int J Dev Neurosci 26:141-145. CrossRef Medline

Nguyen T, Lindner R, Tedeschi A, Forsberg K, Green A, Wuttke A, Gaub P, Di Giovanni S (2009) NFAT-3 is a transcriptional repressor of the growthassociated protein 43 during neuronal maturation. J Biol Chem 284: 18816-18823. CrossRef Medline

Okazawa M, Abe H, Katsukawa M, Iijima K, Kiwada T, Nakanishi S (2009) Role of calcineurin signaling in membrane potential-regulated maturation of cerebellar granule cells. J Neurosci 29:2938-2947. CrossRef Medline

Petrovic M, Hummel T (2008) Temporal identity in axonal target layer recognition. Nature 456:800-803. CrossRef Medline

Piper M, Barry G, Hawkins J, Mason S, Lindwall C, Little E, Sarkar A, Smith AG, Moldrich RX, Boyle GM, Tole S, Gronostajski RM, Bailey TL, Richards LJ (2010) NFIA controls telencephalic progenitor cell differentiation through repression of the Notch effector Hes1. J Neurosci 30:91279139. Medline

Piper M, Harris L, Barry G, Heng YH, Plachez C, Gronostajski RM, Richards LJ (2011) Nuclear factor one X regulates the development of multiple cellular populations in the postnatal cerebellum. J Comp Neurol 519: 3532-3548. CrossRef Medline

Puzianowska-Kuznicka M, Shi YB (1996) Nuclear factor I as a potential regulator during postembryonic organ development. J Biol Chem 271: 6273-6282. CrossRef Medline

Quadrato G, Benevento M, Alber S, Jacob C, Floriddia EM, Nguyen T, Elnaggar MY, Pedroarena CM, Molkentin JD, Di Giovanni S (2012) Nuclear factor of activated T cells (NFATc4) is required for BDNF-dependent survival of adult-born neurons and spatial memory formation in the hippocampus. Proc Natl Acad Sci U S A.

Raetzman LT, Siegel RE (1999) Immature granule neurons from cerebella of different ages exhibit distinct developmental potentials. J Neurobiol 38:559-570. CrossRef Medline

Ramoa AS, McCormick DA (1994) Developmental changes in electrophysiological properties of LGNd neurons during reorganization of retinogeniculate connections. J Neurosci 14:2089-2097. Medline

Rossi DJ, Hamann M (1998) Spillover-mediated transmission at inhibitory synapses promoted by high affinity alpha6 subunit GABA(A) receptors and glomerular geometry. Neuron 20:783-795. CrossRef Medline

Rossi P, De Filippi G, Armano S, Taglietti V, D’Angelo E (1998) The weaver mutation causes a loss of inward rectifier current regulation in premigratory granule cells of the mouse cerebellum. J Neurosci 18:3537-3547. Medline

Sato M, Suzuki K, Yamazaki H, Nakanishi S (2005) A pivotal role of calcineurin signaling in development and maturation of postnatal cerebellar granule cells. Proc Natl Acad Sci U S A 102:5874-5879. CrossRef Medline

Shaikh TH, Haldeman-Englert C, Geiger EA, Ponting CP, Webber C (2011) Genes and biological processes commonly disrupted in rare and heterogeneous developmental delay syndromes. Hum Mol Genet 20:880-893. CrossRef Medline
Sohya K, Kitamura A, Akaneya Y (2007) Chronic membrane depolarizationinduced morphological alteration of developing neurons. Neuroscience 145: 232-240. CrossRef Medline

Strick PL, Dum RP, Fiez JA (2009) Cerebellum and nonmotor function. Annu Rev Neurosci 32:413-434. CrossRef Medline

Tia S, Wang JF, Kotchabhakdi N, Vicini S (1996) Developmental changes of inhibitory synaptic currents in cerebellar granule neurons: role of GABA(A) receptor alpha 6 subunit. J Neurosci 16:3630-3640. Medline

Tripodi M, Arber S (2012) Regulation of motor circuit assembly by spatial and temporal mechanisms. Curr Opin Neurobiol 22:615-623. CrossRef Medline

Tyzio R, Ivanov A, Bernard C, Holmes GL, Ben-Ari Y, Khazipov R (2003) Membrane potential of CA3 hippocampal pyramidal cells during postnatal development. J Neurophysiol 90:2964-2972. CrossRef Medline

Vashishta A, Habas A, Pruunsild P, Zheng JJ, Timmusk T, Hetman M (2009) Nuclear factor of activated T-cells isoform c4 (NFATc4/NFAT3) as a mediator of antiapoptotic transcription in NMDA receptor-stimulated cortical neurons. J Neurosci 29:15331-15340. CrossRef Medline

Wang DD, Kriegstein AR (2009) Defining the role of GABA in cortical development. J Physiol 587:1873-1879. CrossRef Medline

Wang W, Stock RE, Gronostajski RM, Wong YW, Schachner M, Kilpatrick DL (2004) A role for nuclear factor I in the intrinsic control of cerebellar granule neuron gene expression. J Biol Chem 279:53491-53497. CrossRef Medline

Wang W, Qu Q, Smith FI, Kilpatrick DL (2005) Self-inactivating lentiviruses: versatile vectors for quantitative transduction of cerebellar granule neurons and their progenitors. J Neurosci Methods 149:144-153. CrossRef Medline

Wang W, Mullikin-Kilpatrick D, Crandall JE, Gronostajski RM, Litwack ED, Kilpatrick DL (2007) Nuclear factor I coordinates multiple phases of cerebellar granule cell development via regulation of cell adhesion molecules. J Neurosci 27:6115-6127. CrossRef Medline

Wang W, Crandall JE, Litwack ED, Gronostajski RM, Kilpatrick DL (2010) Targets of the nuclear factor I regulon involved in early and late development of postmitotic cerebellar granule neurons. J Neurosci Res 88:258265. CrossRef Medline

Wang W, Shin Y, Shi M, Kilpatrick DL (2011) Temporal control of a dendritogenesis-linked gene via REST-dependent regulation of nuclear factor I occupancy. Mol Biol Cell 22:868-879. CrossRef Medline

Weyer A, Schilling K (2003) Developmental and cell type-specific expression of the neuronal marker NeuN in the murine cerebellum. J Neurosci Res 73:400-409. CrossRef Medline

Yang TT, Xiong Q, Enslen H, Davis RJ, Chow CW (2002) Phosphorylation of NFATc4 by 38 mitogen-activated protein kinases. Mol Cell Biol 22: 3892-3904. CrossRef Medline

Zheng T, Santi MR, Bovolin P, Marlier LN, Grayson DR (1993) Developmental expression of the alpha 6 GABAA receptor subunit mRNA occurs only after cerebellar granule cell migration. Brain Res Dev Brain Res 75: 91-103. Medline

Zhou FM, Hablitz JJ (1996) Postnatal development of membrane properties of layer I neurons in rat neocortex. J Neurosci 16:1131-1139. Medline

Zhou H, Hughes DE, Major ML, Yoo K, Pesold C, Costa RH (2001) Atypical mouse cerebellar development is caused by ectopic expression of the forkhead box transcription factor HNF-3beta. Gene Expr 9:217-236. Medline 